\title{
Essential requirement of cytochrome $c$ release for caspase activation by procaspase-activating compound defined by cellular models
}

\author{
M Seervi ${ }^{1}$, J Joseph ${ }^{1}$, PK Sobhan ${ }^{1}$, BC Bhavya ${ }^{1}$ and TR Santhoshkumar, ${ }^{*}, 1$
}

\begin{abstract}
Mitochondrial cytochrome $c$ (cyt. c) release and caspase activation are often impaired in tumors with Bcl-2 overexpression or Bax and Bak-defective status. Direct triggering of cell death downstream of Bax and Bak is an attractive strategy to kill such cancers. Small molecule compounds capable of direct caspase activation appear to be the best mode for killing such tumors. However, there is no precise model to screen such compounds. The currently employed cell-free systems possess the inherent drawback of lacking cellular contents and organelles that operate in integrating cell death signaling. We have developed highly refined cell-based approaches to validate direct caspase activation in cancer cells. Using this approach, we show that PAC-1 (first procaspase-activating compound), the first direct activator of procaspases identified in a cell-free system, in fact requires mitochondrial cyt. $c$ release for triggering caspase activation similar to other antitumor agents. It can induce significant caspase activation and cell death in the absence of Bax and Bak, and in cells overexpressing Bcl-2 and Bcl-xL. This study for the first time defines precise criteria for the validation of direct caspase-activating compounds using specialized cellular models that is expected to accelerate the discovery of potential direct caspase activators.
\end{abstract}

Cell Death and Disease (2011) 2, e207; doi:10.1038/cddis.2011.90; published online 8 September 2011

Subject Category: Cancer

Caspase activation essentially requires cytochrome $c$ (cyt. $c$ ), Apaf- 1 and procaspase- 9 to be recruited in the apoptosome complex in the cytosol, thereby necessitating the release of cyt. $c$ from mitochondria as a crucial event of programmed cell death. ${ }^{1,2}$ So, caspase activation is initiated only after Bax and Bak-dependent cyt. $c$ release, a process that is often inhibitable by antiapoptotic Bcl-2 family proteins. ${ }^{3}$ Aberrant expression of $\mathrm{Bcl}-2$ family proteins correlate well with prognosis and treatment outcome, and often contributes for drug failure in cancer chemotherapy. ${ }^{4}$ Hypothetically, direct targeting of downstream proteins of the apoptotic cascade by therapeutic agents will be an ideal and successful strategy in killing such resistant tumors. Direct caspase activators, especially that of executioner caspase-3 have received significant attention because such compounds would be ideal in killing cancers with aberrant pro- and antiapoptotic protein expression. ${ }^{5}$ Recently two independent research groups identified several direct caspase activators using cell-free assay systems. ${ }^{6,7}$ The first procaspaseactivating compound (PAC-1) shown to activate procaspase- 3 to caspase- 3 by sequestering inhibitory zinc ions, created significant interest in the scientific community because of its potential to form the basis of new antineoplastic therapeutics. ${ }^{8,9}$

Even though cell-free system of caspase activation is ideal to identify lead molecules from large compound libraries, it is doubtful that such hits, which convert recombinant procaspase-3 to caspase-3 in defined buffer system, can indeed generate active caspase- 3 in cells where multiple proteins and organelles contribute for caspase activation. Considering the tremendous potential of such compounds in addressing clinical drug resistance, it is important to define the minimum molecular signatures in defined cell models to pick up direct caspase activators from classical caspase-activating compounds. Indeed, it is a challenge to define the border line between direct and indirect caspase activation, considering the complex network of signaling that often proceeds rapidly, once initiated, with multiple complex feedback mechanisms. ${ }^{10,11}$

Considering the dominant role of cyt. $c$ in the initiation of caspase activation, by theory, if direct caspase-3 activation is possible, caspase activity can be detected well before cyt. $c$ release or without its release. ${ }^{12}$ In order to define direct caspase activation, we employed live cell-based systems to evaluate cyt. $c$ release, mitochondrial outer membrane permeabilization and caspase activation in real time and hierarchical manner. ${ }^{13}$ Our study using such tools suggests that PAC-1 requires cyt. $c$ release from mitochondria, and Apaf-1 for caspase-3 activation. However, PAC-1 is a potential drug to bypass the $\mathrm{Bcl}-2 / \mathrm{Bcl}-\mathrm{xL}$ resistance and is capable to induce Bax and Bak-independent cell death effectively. The cellular model described here can form an

\footnotetext{
${ }^{1}$ Integrated Cancer Research Program, Rajiv Gandhi Centre for Biotechnology, Thiruvananthapuram, India

${ }^{*}$ Corresponding author: TR Santhoshkumar, Integrated Cancer Research Program, Rajiv Gandhi Centre for Biotechnology, Thycaud P.O, Thiruvananthapuram, Kerala 695014, India. Tel: + 91471234 1716; Fax: + 91471234 8096; E-mail: trsanthosh@rgcb.res.in

Keywords: cancer drug resistance; direct caspase activation; cytochrome $c$; apoptosis; mitochondria

Abbreviations: cyt. $c$, cytochrome $c$; EGFP, enhanced green fluorescent protein; EYFP, enhanced yellow fluorescent protein; MEF, mouse embryonic fibroblast; FRET, fluorescence resonance energy transfer; TMRM, tetramethyl-rhodamine methyl ester; $\Delta \psi_{\mathrm{m}}$, mitochondrial membrane potential, PAC-1, first procaspaseactivating compound

Received 13.4.11; revised 10.6.11; accepted 30.6.11; Edited by A Finazzi-Agró
} 
ideal platform for identifying potential direct caspase-activating compounds, as well as in defining the minimum criteria for distinguishing direct caspase activators from classical apoptosis inducing compounds.

\section{Results}

Tracking of cyt. $c$ release in real time. Apoptosome complex assembly and activation of procaspase- 9 , is initiated in the cytosol only after the release of cyt. $c$ from mitochondria to cytosol. ${ }^{2}$ Theoretically, if direct caspase activation is possible, it would generate cytosolic active caspase well before cyt. $c$ release. Therefore, the primary goal was to develop cellular models to define direct caspase activation from classical apoptosis by kinetic evaluation of cyt. $c$ release and caspase activation systematically in live cells. We generated several cancer cell lines expressing cyt. $c$ stably with enhanced green fluorescent protein (EGFP) fusion. The correct targeting and its potential to release upon apoptosis were evaluated by imaging using multiple drugs. The representative images of $\mathrm{SiHa}$ cyt. $c$-EGFP stable cells expressing mitochondrial-targeted DsRed and its response with different drugs is shown (Supplementary Figure S1a). Employing these cellular models, we evaluated cyt. $c$ release by the first reported procaspase- 3 activating small molecule, PAC-1. It induced significant cyt. $c$ release in SW480 and $\mathrm{SiHa}$ cells, and none of the cells under study showed evidence of cell death without cyt. $c$ release (Supplementary Figures S1b and c).

For tracking cyt. $c$ release and its dependency on caspase-3 in a real time manner, we carried out live-cell imaging in endogenous caspase-3-expressing SW480, caspase-3deficient MCF7 and caspase-3-expressing MCF7(MCFC3) cells (Supplementary Videos S1, S2 and S3; Figures 1a-c). Time-lapse imaging suggested that cyt. $c$ release was initiated before $6 \mathrm{~h}$ in SW480 cells upon PAC-1 treatment. Surprisingly, in MCF7 and MCFC3 cells, cyt. $c$ release was initiated almost at the same time, that is, around 8-9 h after PAC-1 treatment. Remarkably, MCFC3 cells underwent rapid cell death than MCF7 cells after cyt. $c$ release, as evident from the morphological changes and nuclei condensation. Immunoblot also substantiated the cyt. $c$ release kinetics to be consistent with imaging data (Figures $1 \mathrm{a}-\mathrm{c}$ ). The results indicate that PAC-1 induces cyt. $c$ release in a caspase- 3 independent manner but in the presence of caspase-3, cells undergo rapid death after cyt. $c$ release consistent with its potential ability to accelerate cell death. Furthermore, we analyzed cyt. $c$ release in MCFC3 cyt. c-EGFP cells using various concentration of PAC-1, which substantiated that cyt. $c$ release was delayed significantly below $30 \mu \mathrm{M}$ of PAC-1 concentration (Supplementary Figure S2a and b).

Tracking of caspase activation in real time. The integration of cyt. $c$ release kinetics with temporal information of caspase activation in the same cells is a prerequisite to rule out the cyt. $c$-dependent or -independent pattern of caspase activation. As the time gap between cyt. $c$ release and caspase activation is known to vary significantly between cells, it is quite possible that rare events are likely to be missed in end-point assays. This necessitates the need for a live cell-based approach to monitor caspase activation in real time. We have employed a fluorescence resonance energy transfer (FRET) probe-based caspase activation sensor consisting of donor ECFP and acceptor enhanced yellow fluorescent protein (EYFP) fluorophores linked to caspase-3, 7 specific amino-acid linker DEVD (Figure 2a) as described. ${ }^{14-16}$ As DEVD is also a preferable substrate for active caspase-8, any DEVD activity also indirectly reflects the initiator caspase- 8 activity, indicating that any caspase activity without cyt. $c$ release can be scored for possible direct caspase activation. ${ }^{17}$ By employing FRET probe expressing cell models, we noticed that FRET loss was initiated only by $12 \mathrm{~h}$ after PAC-1 treatment in SW480 cells, which increased rapidly at further time points (Figure $2 \mathrm{~b}$ and Supplementary Video S4). DEVD and caspase-3 cleavage was substantiated by immunoblot that were detected only at $12 \mathrm{~h}$ upon PAC-1 treatment (Figure 2b). Surprisingly, there was significant DEVD cleavage even in the absence of caspase-3 (MCF7), which was initiated around $12 \mathrm{~h}$ upon PAC-1 treatment, and reconstitution of caspase-3 (MCFC3) could not induce remarkable difference in the initiation time of DEVD cleavage (Figures 2c and d; Supplementary Videos S5a, b and S6). However, cells died rapidly after FRET loss in case of MCFC3 cells as reflected from the loss of cells in imaging area (Figure 2d). The same results were also obtained for DEVD cleavage in western blot (Figures $2 c$ and d). The comparison of temporal data of cyt. $c$ release from the previous experiments and live cell caspase activation readouts indirectly suggested that there is no detectable caspase activation before cyt. $c$ release in any of the cells. Furthermore, cyt. c-EGFP-overexpressing cells were incubated with intracellular caspase substrate CaspaTag sulforhodamine (caspase-3,7) after treating with PAC-1 and as expected, many cells were observed without caspase activity even after significant release of cyt. $c$ (Supplementary Figure S3a, upper two panels). Thus, it is clear that PAC-1 induced cyt. $c$ release before caspase activation in all these cell lines.

Overall, although carried out as independent experimental systems, our results show that correlating the two critical events of apoptosis, cyt. $c$ release and caspase activation as analyzed in real time, can differentiate direct caspase activation from classical apoptosis where cyt. $c$ release remains as an initiator for caspase activity. The results show that cyt. $c$ release is clearly an event upstream to caspase activation in PAC-1-mediated cell death and is independent of caspase-3.

Comparative study of cell death in the presence and absence of procaspase-3. Caspase-3 dependency of PAC-1-induced cell death was supported by the data of cell death in multiple normal and cancer cell lines that strongly placed caspase-3 expression as a deciding factor for its cytotoxicity. ${ }^{7}$ So, in order to further validate the caspase-3 dependency, we compared cell death in the presence (MCFC3) and absence of caspase-3 (MCF7). Surprisingly, PAC-1 induced chromatin condensation even in MCF7 cells after $24 \mathrm{~h}$ and almost $60 \%$ cells showed condensed nuclei after $48 \mathrm{~h}$ of treatment although it was earlier and more in 

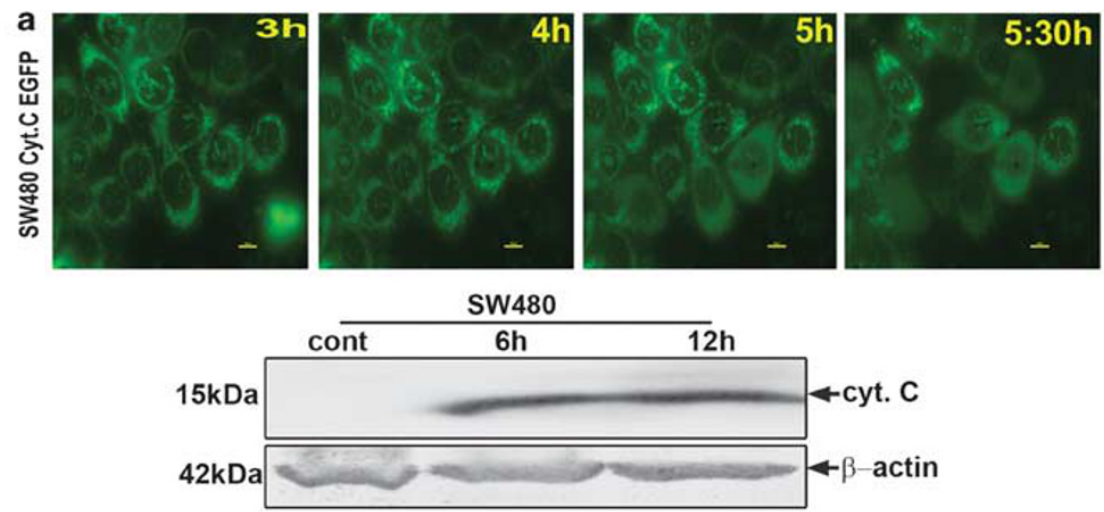

b

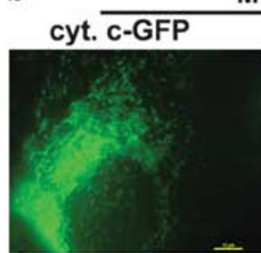

MCF7 Cyt.C-EGFP
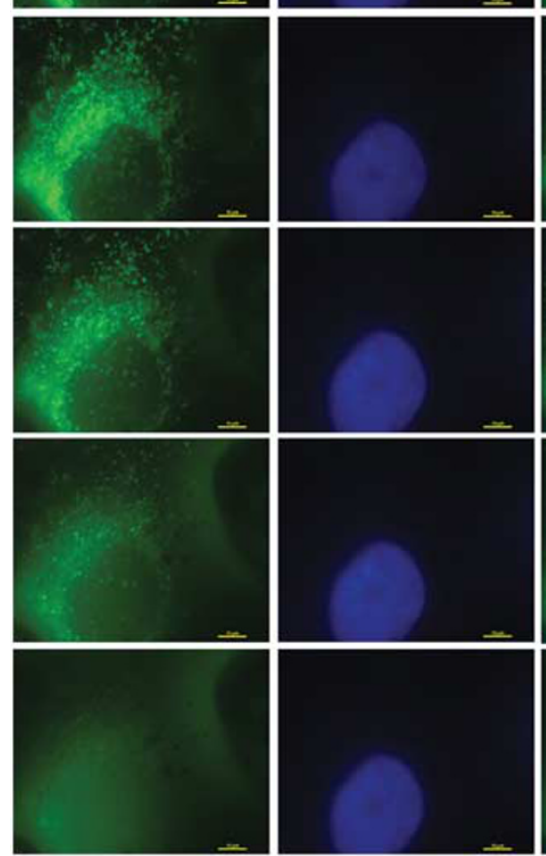

MCF7

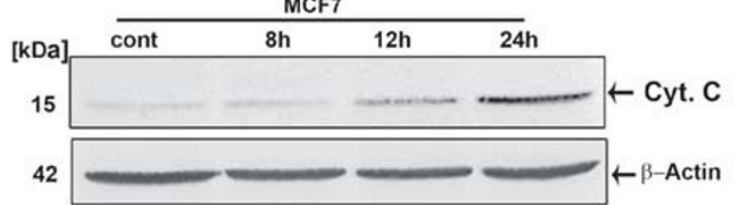
merged c

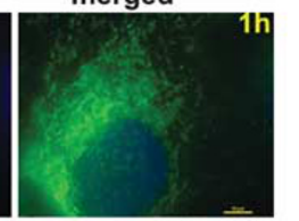

$8 \mathrm{~h}$
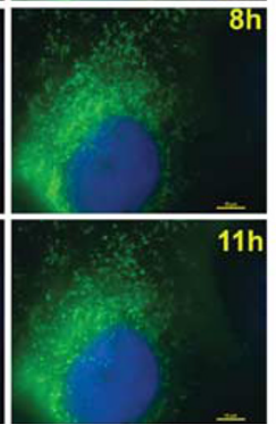

$14 \mathrm{~h}$
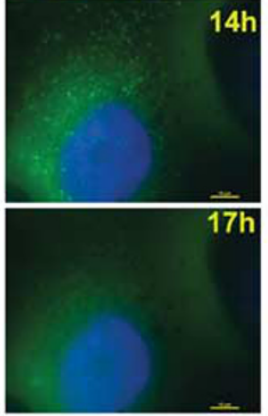

$7 \mathrm{~h}$
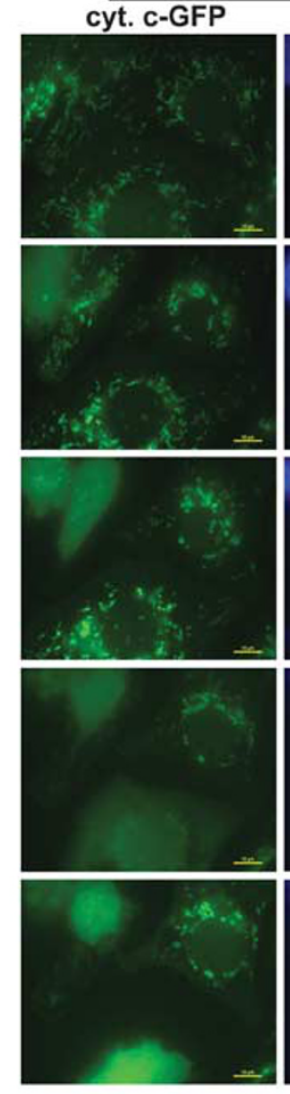

MCFC3 cyt. c-EGFP
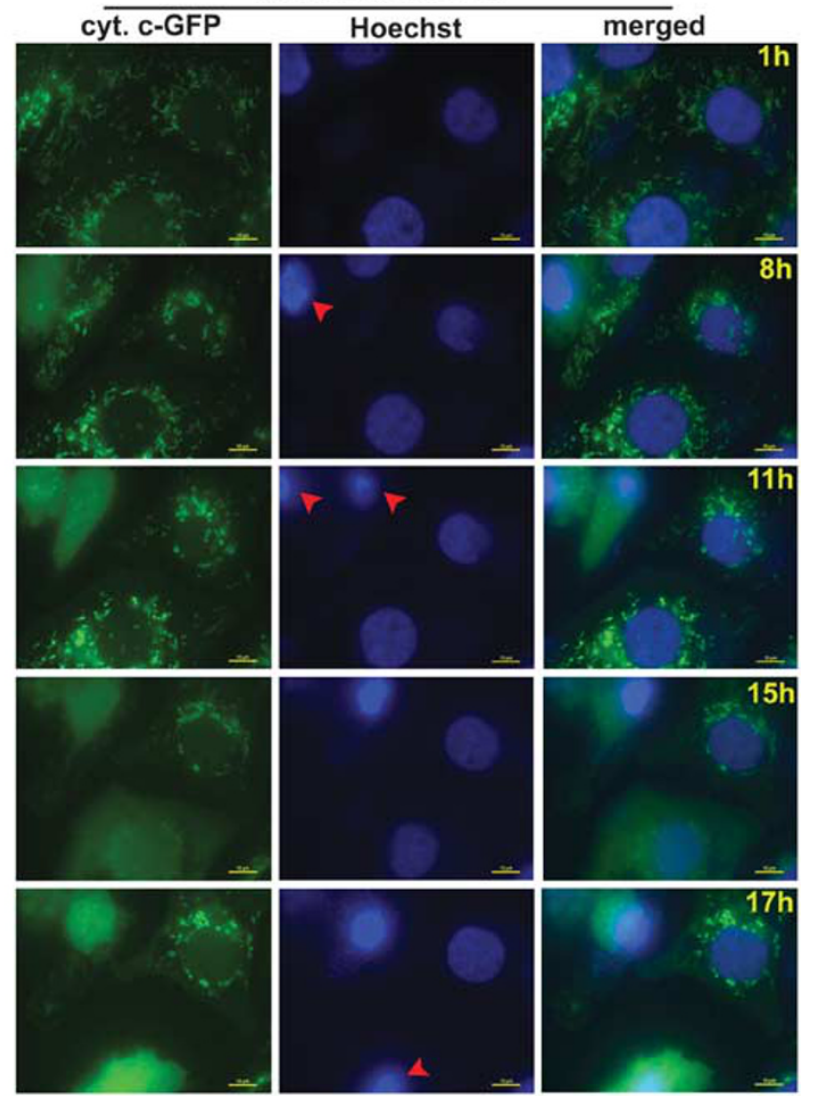

MCF C3

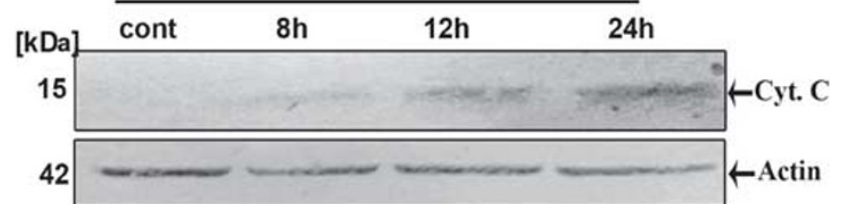

Figure 1 Cell-based model to study kinetics of cyt. c release. (a) SW480 cyt. c-EGFP-expressing cells were treated with PAC-1 and after 3 h, time-lapse imaging was done by live-cell fluorescent microscopy at time intervals of $30 \mathrm{~min}$. The representative images are shown (scale bar: $10 \mu \mathrm{m}$. SW480 cells were treated by PAC-1 for indicated time points and cyt. crelease was checked by immunoblot in cytosolic fraction after digitonin permeabilization. (b) Caspase-3 lacking MCF7 cells were stably transfected with cyt. c-EGFP and treated with PAC-1 after staining with Hoechst. Live cell time-lapse imaging was done by fluorescent microscopy with a time interval of 15 min. Representative images of indicated time points are shown (scale bars: $10 \mu \mathrm{m}$ ). Diffuse pattern indicated the cyt. c release from mitochondria to cytosol, which is initiated around $8 \mathrm{~h}$ but nucleus was not condensed even up to $16 \mathrm{~h}$. The cyt. $c$ release was also checked by western blot in cytosolic fraction of PAC-1 treated MCF7 cells after digitonin permeabilization. (c) Caspase-3-expressing MCFC3 cells were stably transfected with cyt. cEGFP and treated with PAC-1 after Hoechst staining. Time-lapse imaging was done at time intervals of $20 \mathrm{~min}$. Representative images are shown (scale bars: $10 \mu \mathrm{m}$ ) and the results were also substantiated by western blot in MCF C3 cells after drug treatment as earlier. The fragmentation of cells after cyt. $c$ release is rapid in caspase-3-expressing cells compared with MCF7. The arrows represent the condensed nucleus after cyt. $c$ release. But, the initiation of cyt. $c$ release was almost at same time point in both the cells (around 8-9h) 

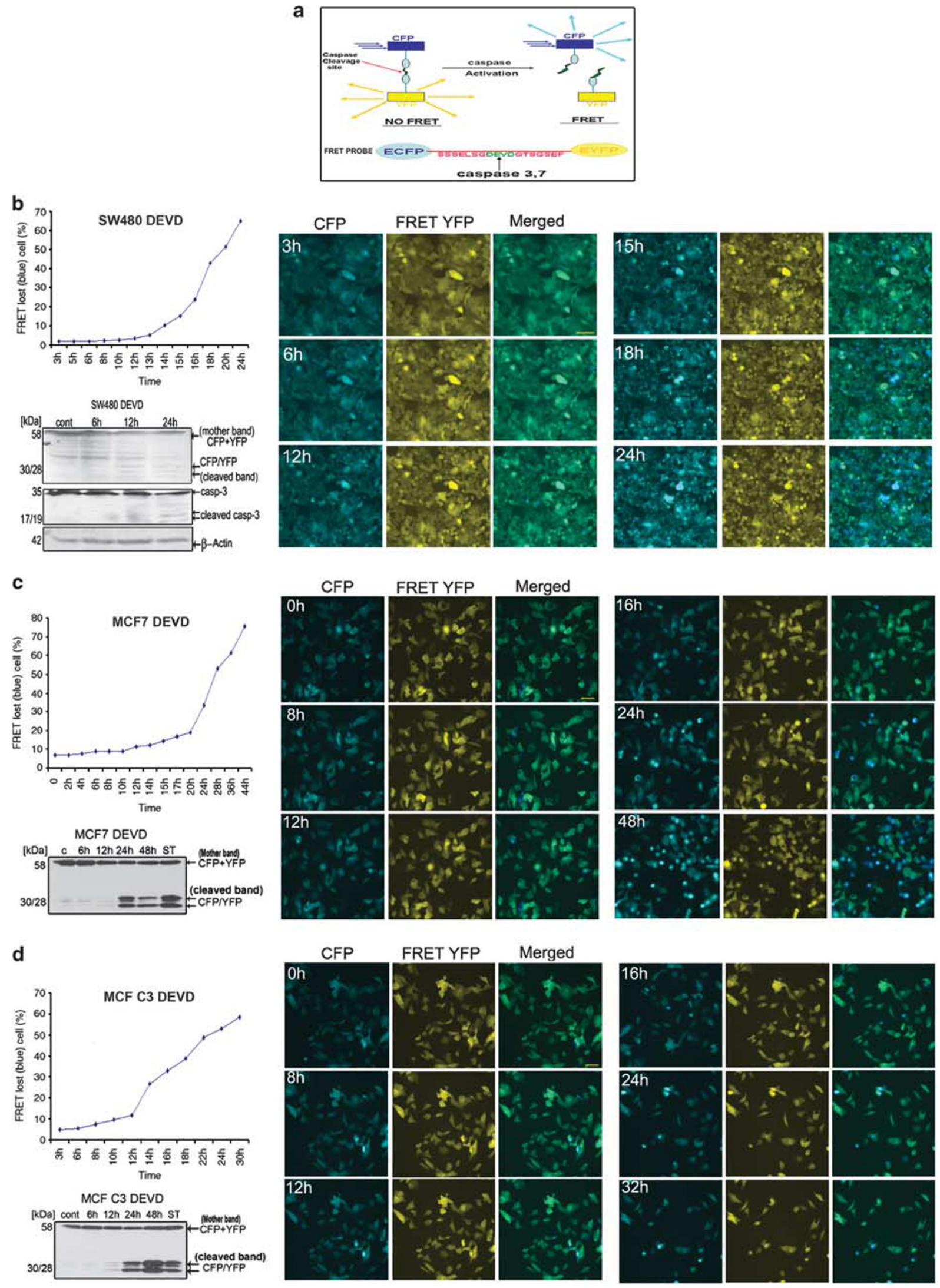
MCFC3 cells (Figure 3a). Long-term clonogenic survival (Figure $3 b$ ), also suggested that PAC-1 can target MCF7 cells. In both the experiments, MCFC3 cells were more sensitized to PAC-1 as has been already reported for several drugs. Quite interestingly, we noticed that mitochondrial membrane potential $\left(\Delta \psi_{\mathrm{m}}\right)$ loss was initiated early in both the cells at $8 \mathrm{~h}$ after treatment, and it was more pronounced at later time points indicating a prominent role of mitochondria in the apoptosis induced by PAC-1 (Figure 3c). Cleavage of caspase- 3 in MCFC3 cells was evident by $12 \mathrm{~h}$ after PAC-1 treatment in western blot, again validating our previous FRET probe readouts. Activation of other caspases like caspase-7, 8, 2, 9 as well as PARP-1 cleavage was also more in MCFC3 cells than MCF7 cells (Figure $3 d$ ). Caspase inhibitors failed to alter the release of cyt. $c$ in MCF7 cells indicating that its release is independent of any undetectable caspase activity (Supplementary Figure S3b). Furthermore, $\Delta \psi_{\mathrm{m}}$ loss is an early event, which is initiated even in the absence of caspase-3, suggesting the role of mitochondria-mediated apoptosis by PAC-1. The results suggest that PAC-1 can induce caspase activation in both MCF7 and MCFC3 cells, and the presence of caspase-3 probably augments the cell death by feedback mechanism.

$\Delta \psi_{\mathrm{m}}$ loss preceded cyt. $c$ release and caspase activation. As there is no consensus regarding the kinetics of $\Delta \psi_{\mathrm{m}}$ loss and cyt. $c$ release, we analyzed both the events in a kinetic mode after staining MCFC3 and MCF7cells with tetramethyl-rhodamine methyl ester (TMRM). ${ }^{18,19}$ The kinetic study demonstrated that $\Delta \psi_{\mathrm{m}}$ loss preceded cyt. $c$ release after PAC-1 treatment both in the presence and absence of caspase-3 (Supplementary Video S7, Figure 4a, and Supplementary Figure S3c).

Despite extensive studies, the key upstream events critical for the release of cyt. $c$ in drug-induced apoptosis still remains elusive. ${ }^{19}$ Bax conformational activation and its translocation to the mitochondria are some of the early changes that contribute to cyt. $c$ release. ${ }^{3}$ Analysis of $\Delta \psi_{\mathrm{m}}$ loss and Bax mitochondrial translocation employing MCF7 Bax-EGFP cells by live-cell imaging showed loss of TMRM intensity just before Bax translocation in PAC-1-induced apoptosis, indicating that the signaling proceeds in sequence of $\Delta \psi_{\mathrm{m}}$ loss - Bax translocation - cyt. $c$ release and DEVD activity (Supplementary Figure S4a). Also, time-lapse imaging of MCF7 BidDsRed-expressing cells treated with PAC-1 failed to show any indication of Bid translocation (Supplementary Figure S4b).

In general, the role of mitochondria in the initiation process of apoptosis can be conclusively ascertained from the above sequence of early events of apoptosis and caspase activation determined using live cell-based tools as described. However, to get meaningful quantitative information, readout from a large population of cells for both $\Delta \psi_{\mathrm{m}}$ loss and caspase activation is essential for large compound library screening. So, we have adapted the FRET probe expressing cells for simultaneous analysis of FRET ratio and $\Delta \psi_{\mathrm{m}}$ loss by highthroughput imaging in FRET probe expressing $\mathrm{SiHa}$ and MCF7 cells (Supplementary Figure S5a). If there is FRET loss without $\Delta \psi_{\mathrm{m}}$ loss, mitochondria-independent caspase activation can be scored. The scatter plot demonstrated that TMRM intensity is significantly reduced in all cells that showed FRET ratio change from the control (Figures $4 b$ and $c$ ). We did not observe any cell with FRET loss without $\Delta \psi_{\mathrm{m}}$ loss upon treatment with PAC-1. The results point that $\Delta \psi_{\mathrm{m}}$ loss occurred before caspase activation. The data were also substantiated by live-cell imaging of FRET probe expressing MCF7 and MCFC3 cells in real time manner stained with TMRM before PAC-1 treatment (Supplementary Figure S5b, lower two panels). Overall, the study substantiated the importance of these cellular models to fish out direct caspase activators and also indicated that PAC-1 induces $\Delta \psi_{\mathrm{m}}$ loss followed by cyt. $c$ release, which subsequently triggers downstream caspase-3 activation like any other classical apoptosis inducing drug.

$\mathrm{Bcl}-2$ and $\mathrm{Bcl}-\mathrm{xL}$ overexpression slightly reduced cyt. $c$ release, delayed caspase activation and cell death. The most promising feature of direct activation of caspases in cancers is its possible ability to be killed cells with acquired drug resistance due to loss of proapoptotic proteins like Bax or Bak, and overexpression of antiapoptotic proteins like Bcl-2 and Bcl-xL. ${ }^{4,20-22 . ~ S u c h ~ c e l l s ~ a r e ~ c o m m o n ~ i n ~ m o s t ~ s o l i d ~}$ tumors and are difficult to be killed by conventional antitumor agents that promote cell death through cyt. $c$-dependent caspase activation. Therefore, to know the role of Bcl-2 and $\mathrm{Bcl}-\mathrm{xL}$ in PAC-1-mediated cell death, we stably generated MCFC3 cells with Bcl-2-EGFP and Bcl-xL-GFP plasmids (Supplementary Figure S6a). After confirmation of its drugresistant property (Supplementary Figure S6b), cell death was evaluated in these cells by examining nuclear condensation (Figure 5a), $\Delta \psi_{\mathrm{m}}$ loss by TMRM staining (Figure 5c) and cell survival by clonogenicity assay (Figure 5b) after treatment with PAC-1. Compared with anticancer drugs like cis-platin, staurosporine and etoposide, PAC-1 could kill Bcl-2 and Bcl-xL-overexpressing cells in a delayed manner. PAC-1 was able to eliminate $\mathrm{Bcl}-2$ and $\mathrm{Bcl}-\mathrm{xL}$-overexpressing cells efficiently although cell rescue was comparatively higher than MCFC3 cells as observed from the clonogenicity assay.

Figure 2 Cell-based model to track down caspase activation in kinetic mode. (a) The schematic representation of FRET probe ECFP-DEVD-EYFP used for monitoring caspase activation. (b) SW480 cells stably expressing FRET probe were treated with PAC-1 $(100 \mu \mathrm{M})$ and ratio imaging was carried out as described with a time interval of $15 \mathrm{~min}$ after $3 \mathrm{~h}$ of drug addition. The representative images for CFP channel, FRET-YFP channel and merged images at indicated time points are shown (scale bar: $100 \mu \mathrm{m}$ ). Loss of FRET upon caspase activation is reflected in enhanced blue emission with reduction in FRET YFP emission. The change of color from green to blue in the merged channels marks the cells with caspase activation. The percentage of cells with FRET loss (blue cells in merged images) was scored and represented as graph. The cleavage of FRET probe by active caspases was detected by western blot. The appearance of cleaved band of CFP and YFP suggest that DEVD cleavage is initiated at $12 \mathrm{~h}$. Blot was reprobed with Caspase-3 antibody to show the presence of active caspase-3. $\beta$ - actin served as loading control (c and d). Similarly, time-lapse imaging carried out for MCF7 and MCFC3 FRET probe expressing cells and FRET loss cells were scored and represented in graph. DEVD cleavage was also detected by immunoblot. In both the cells, FRET loss initiated by around $12 \mathrm{~h}$ after PAC-1 treatment (scale bar: $100 \mu \mathrm{m}$ ) 
a

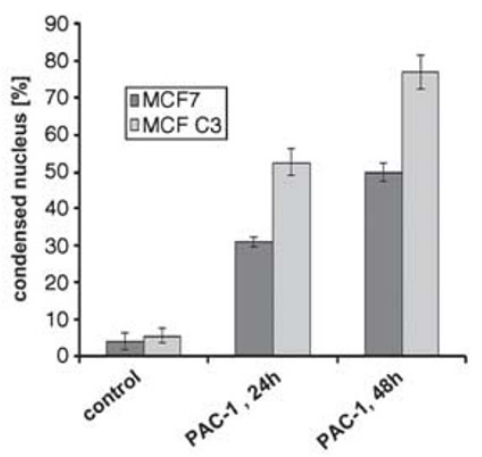

b

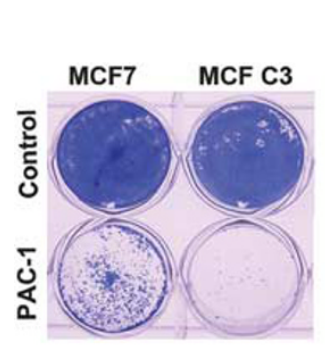

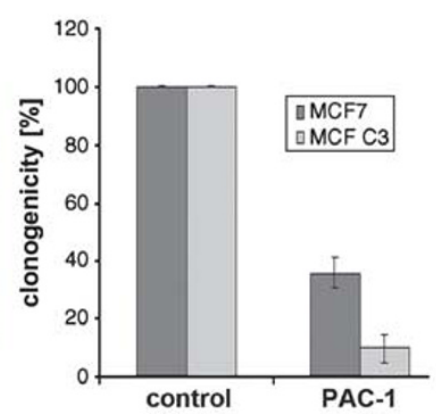

Control

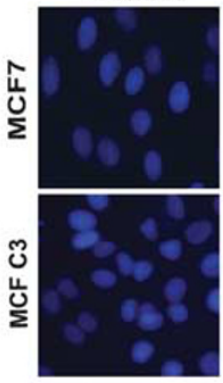

PAC-1, 24h
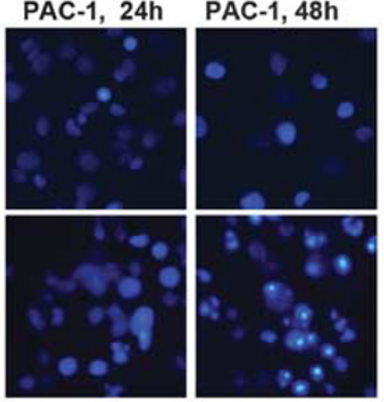
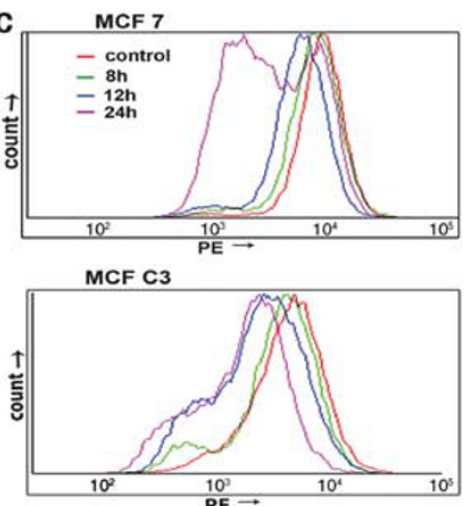

d
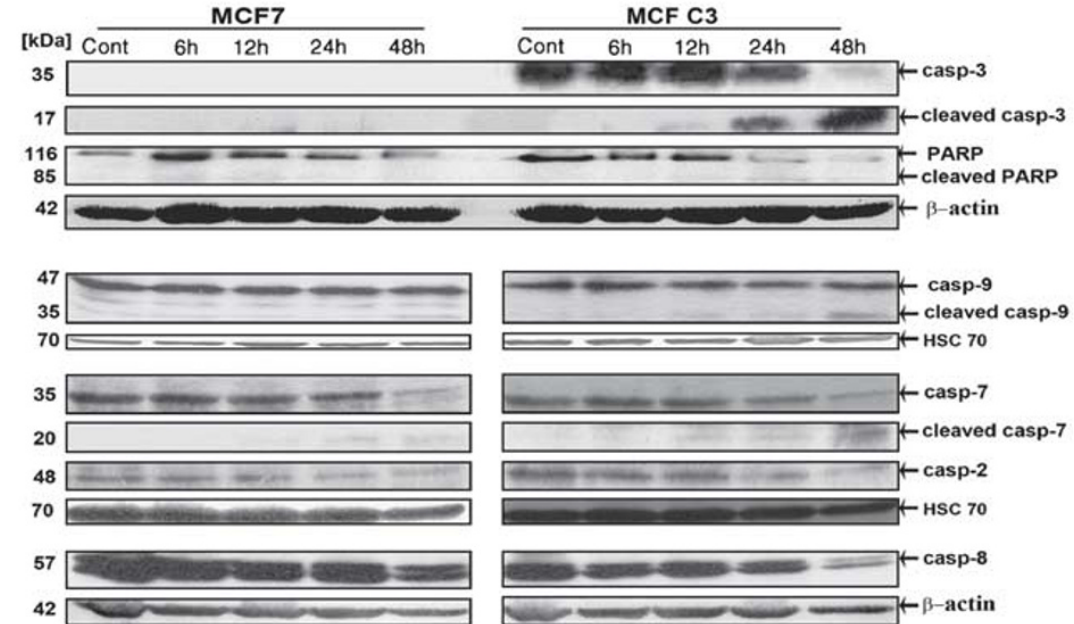

Figure 3 Induction of cell death in presence and absence of caspase-3 by PAC-1. (a) MCF7 (caspase-3-deficient) and MCFC3 (caspase-3-expressing) cells were stained with Hoechst 33342 after PAC-1 $(75 \mu \mathrm{M})$ treatment with different time points. The representative images of Hoechst stained nuclei are shown and percentage of condensed nuclei are represented graphically ( $n=4$, mean \pm S.D.). MCF7 versus MCFC3, $24 \mathrm{~h}$ treatment $(P<0.0015)$ and $48 \mathrm{~h}$ treatment $(P<0.0003)$. (b) Clonogenic survival was assessed after PAC-1 treatment in both these cells and the representative images are shown. The clonogenicity was quantified by reading absorbance after staining with crystal violet as described. The graph represents clonogenic efficiency. ( $n=3$, mean \pm S.D.). PAC-1 treated MCF7 versus MCFC3 $(P<0.0001)$. (c) MCF7 and MCFC3 cells were stained with TMRM after PAC-1 treatment and intensity was analyzed by Flow cytometry (20000 events) to detect the $\Delta \psi_{\mathrm{m}}$ loss in a time-dependent manner. Shifting of population to the left compared with that of the untreated population suggests loss in $\Delta \psi_{\mathrm{m}}$. (d) Caspase activation (caspase-3, $-8,-2,-7,-9$ ) and PARP cleavage were analyzed by western blot in both the cells after PAC-1 treatment with various time points

Figure 4 Mitochondrial membrane potential loss precedes cyt. $c$ release and caspase activation. (a) MCFC3 cells expressing cyt. c-EGFP were stained with TMRM, and $2 \mathrm{~h}$ after drug treatment imaged for both TMRM and EGFP as described. The representative images are shown (scale bar: $10 \mu \mathrm{m}$ ). The TMRM intensity is reduced before cyt. $c$ release. Also, the pixel intensity profile of TMRM (red line) and cyt. c- EGFP (green line) of the indicated cell is shown. This graph and image clearly indicate that $\left(\Delta \psi_{\mathrm{m}}\right)$ loss preceded cyt. $c$ release from mitochondria. (b) SiHa FRET DEVD probe-expressing cells were seeded in 96 -well glass-bottom plate and stained with TMRM before treatment with drugs. Drugs were added in medium containing low concentration of TMRM and images were captured with montage (2x2) at different time points using BD pathway 435 imager to read out large number of cell population. Scatter plot of FRET ratio and TMRM intensity after treatment with PAC-1 are shown. The shifting of population to left side suggests the loss in $\Delta \psi_{\mathrm{m}}$. Arrow marks represent the cells with FRET loss as well as $\Delta \psi_{\mathrm{m}}$ loss. There was no cell detected with FRET loss without $\Delta \psi_{\mathrm{m}}$ loss. (c) MCF7 cells expressing FRET DEVD probe were also used for determining FRET loss and TMRM intensity by BD pathway imager as described above. The arrow marks represent the FRET lost cell populations, which also reflected $\Delta \psi_{\mathrm{m}}$ loss 
a MCF C3 Cyt. C EGFP
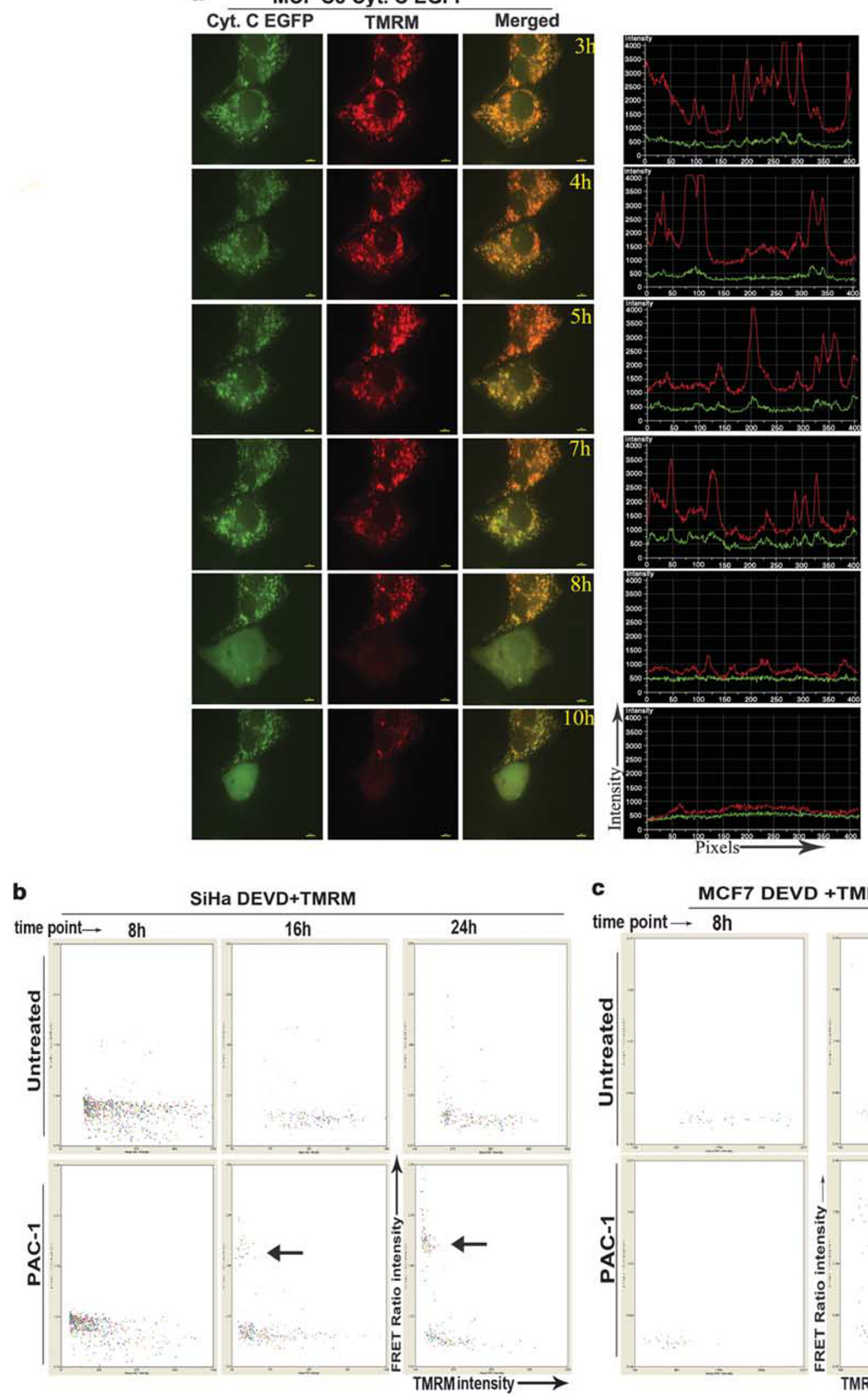

\section{C MCF7 DEVD +TMRM}
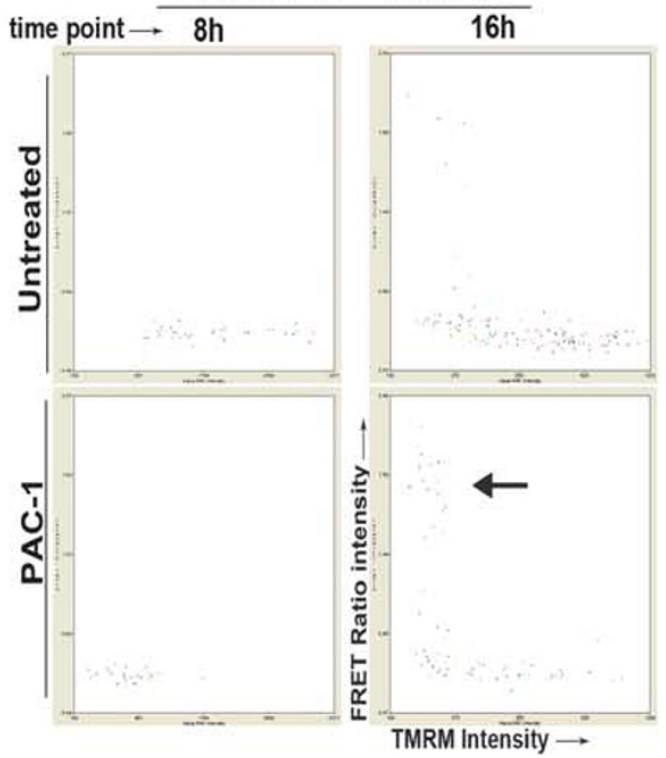

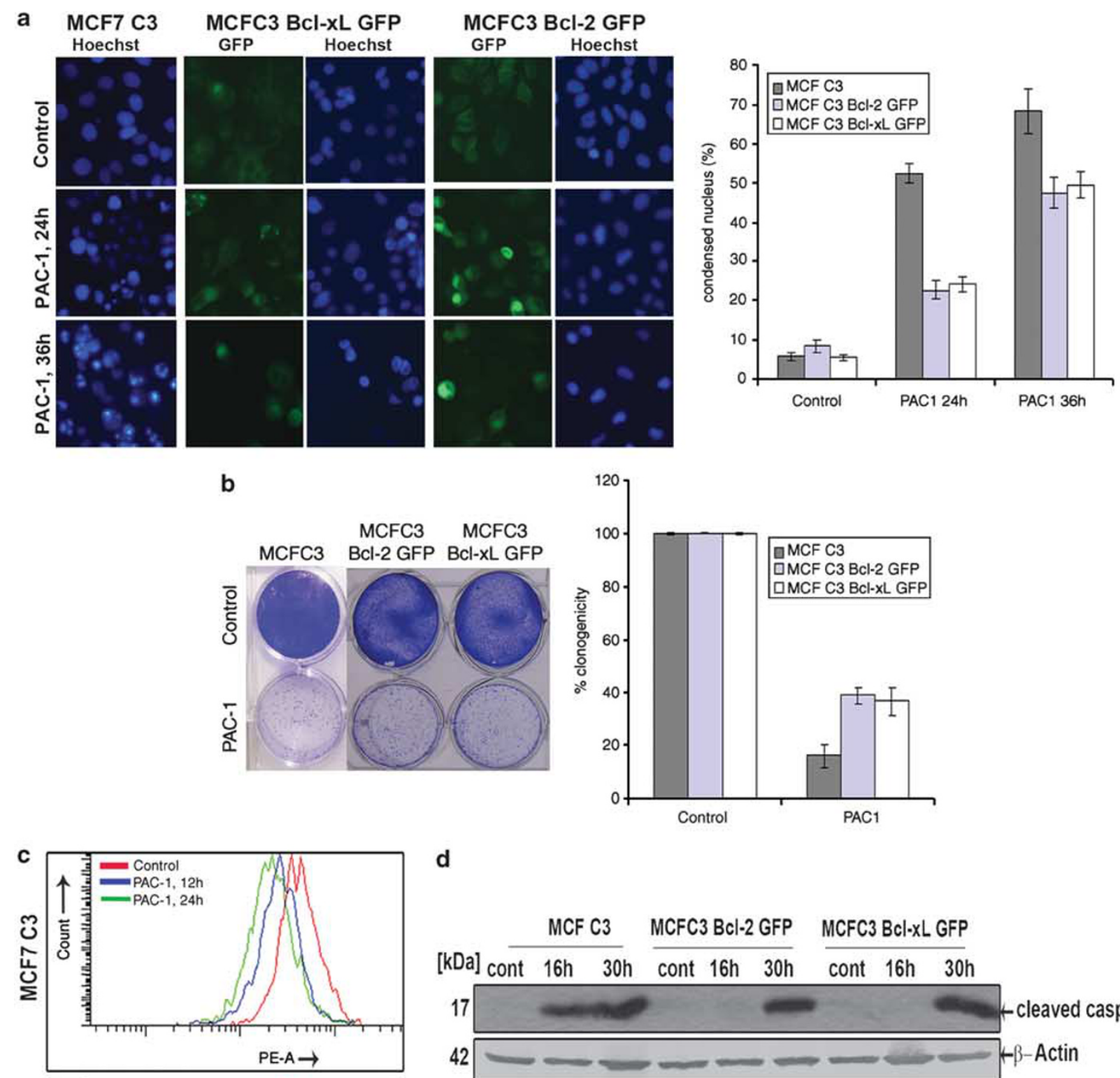

d
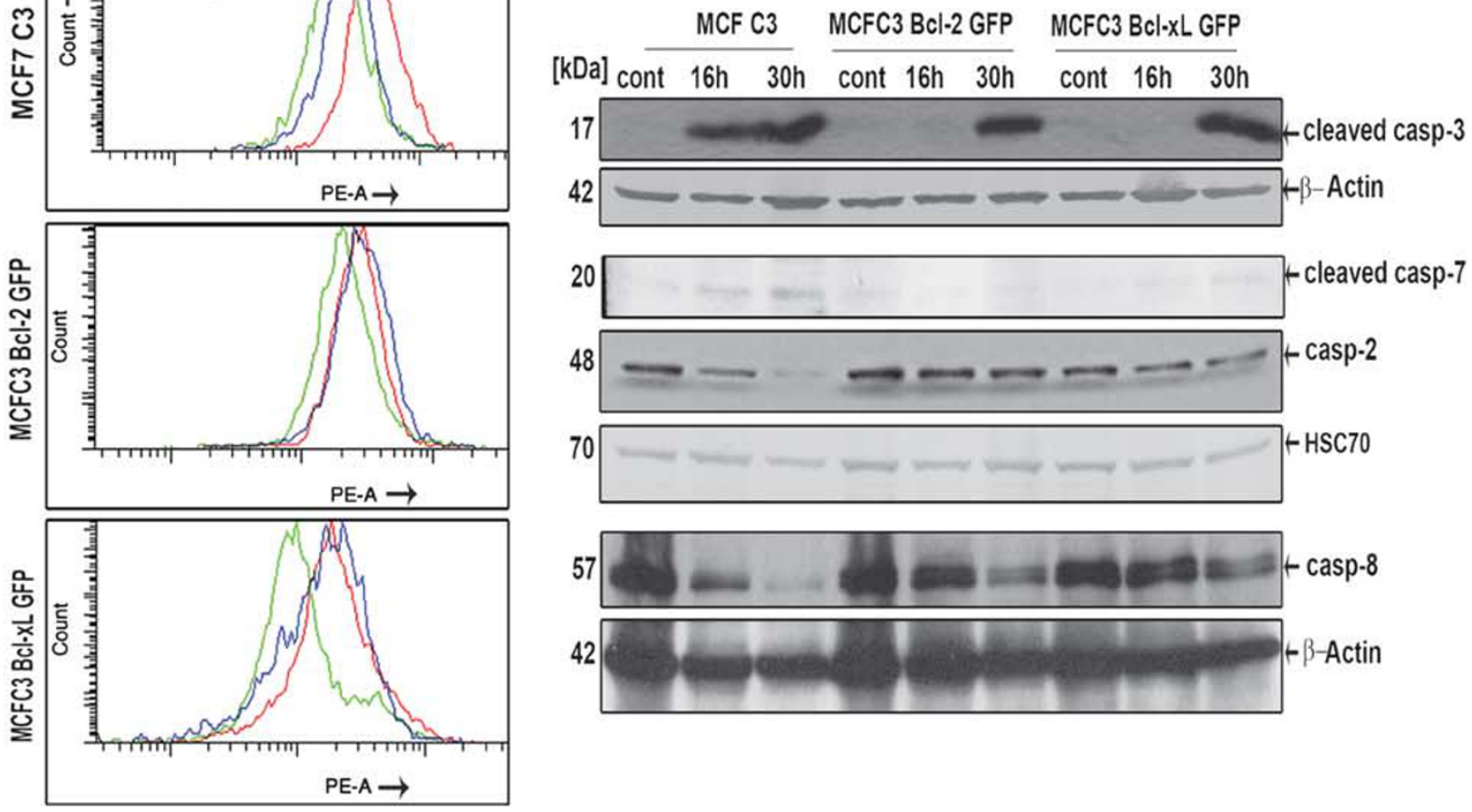

Figure 5 Continue. 

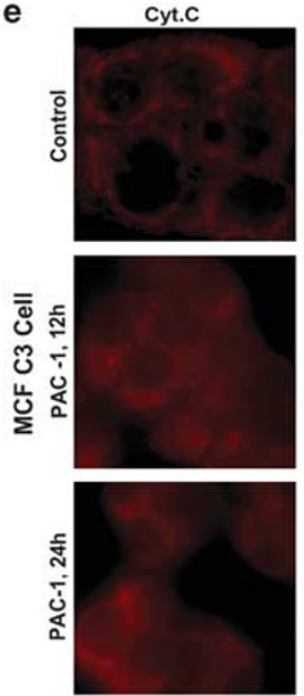

Cyt. C
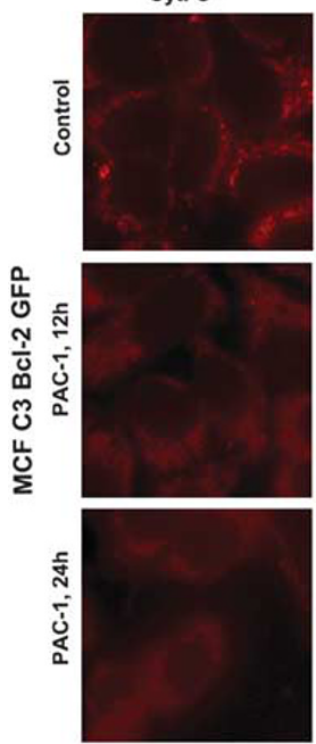

Hoechst
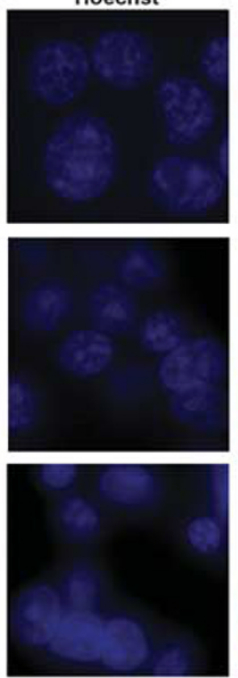

Hoechst
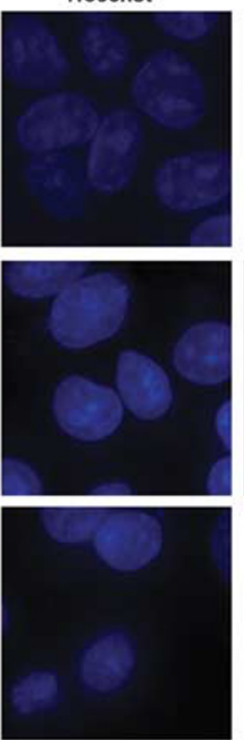

Merged
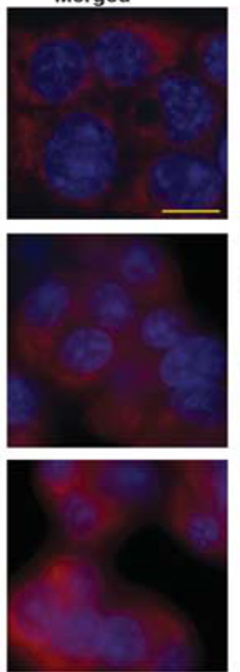

Bcl-2 GFP
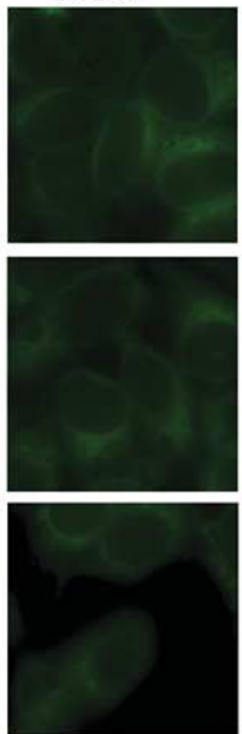

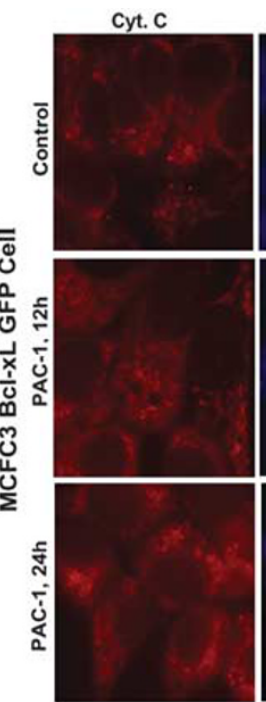

Hoechst

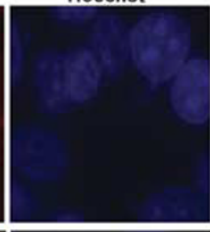

GFP

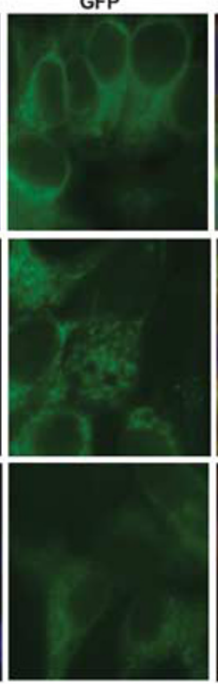

Merged
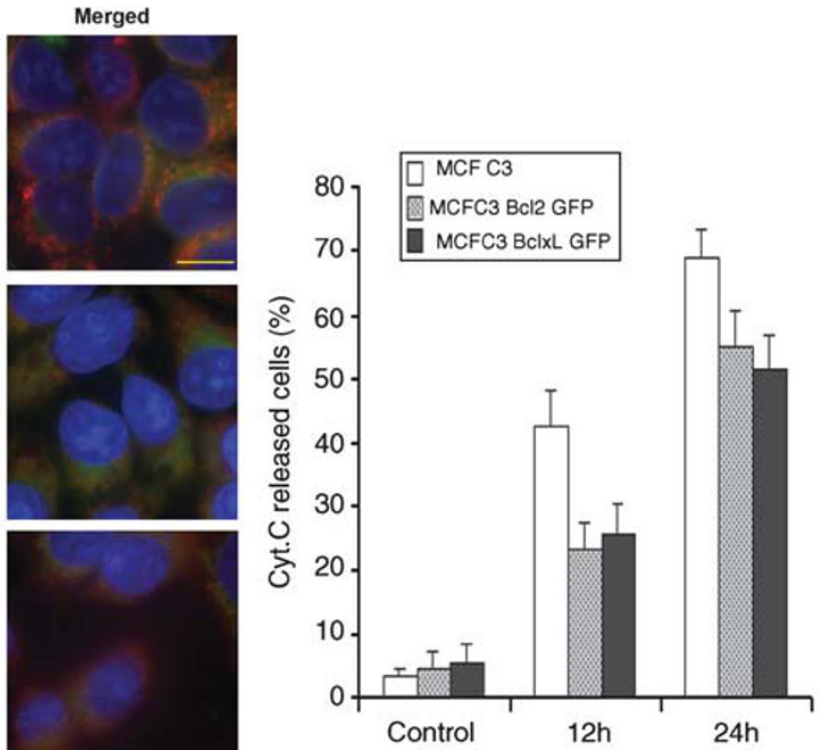

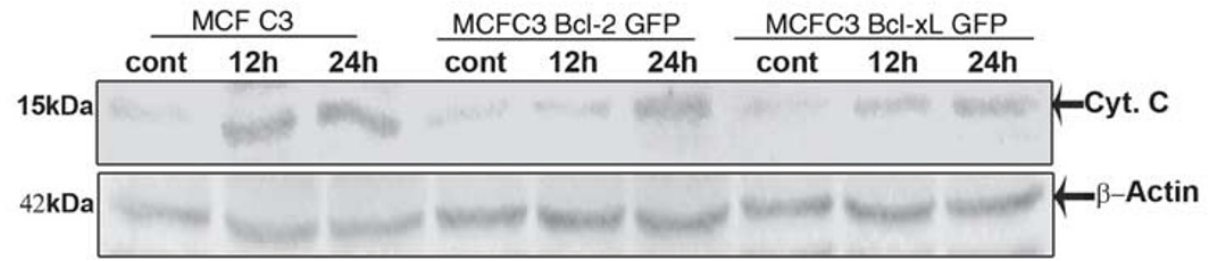

Figure 5 Induction of mitochondrial cyt. c release, caspase activation and cell death in Bcl-2 and Bcl-xL-overexpressing cells. (a) MCFC3 vector control and Bcl-2 GFP, Bcl-xL GFP-overexpressing cells were treated with PAC-1 $(75 \mu \mathrm{M})$ at indicated time points and stained with Hoechst to analyze nuclear condensation. Representative images are shown. The percentage of condensed nuclei relative with untreated cells are represented in graph ( $n=3$, mean \pm S.D.). MCFC3 versus MCFC3Bcl-2-GFP cells, and MCFC3 versus MCFC3Bcl-xL-GFP cells $(P<0.001)$ for both $24 \mathrm{~h}$ and $36 \mathrm{~h}$ treatment. $(\mathrm{b})$ Clonogenic survival was assessed in these cells after PAC-1 treatment. The representative images are shown. The quantitative data of clonogenic efficiency determined as described are shown. MCFC3 versus MCFC3Bcl-2-GFP cells, and MCFC3 versus MCFC3Bcl-xL-GFP cells $(P<0.001)$. (c) Flow cytometry data showing $\Delta \psi_{\mathrm{m}}$ loss in above panel of cell lines after PAC-1 treatment with indicated time points. The TMRM intensity shifting towards lefts side indicates $\left(\Delta \psi_{\mathrm{m}}\right)$ loss. (d) Caspase activation was detected by western blot in these cells upon PAC-1 treatment with different time points. (e) MCFC3 vector cells were treated with PAC-1 $(75 \mu \mathrm{M})$ for $12 \mathrm{~h}$ and $24 \mathrm{~h}$, and immunofluorescence was done for checking cyt. $c$ release using fluorescent microscopy. Representative cyt. $c$ channel (red), nucleus stained with Hoechst (blue) and merged images are shown (scale bar: $10 \mu \mathrm{m}$ ). The cyt. $c$ immunofluorescent images of MCFC3 Bcl2-GFP-overexpressing cells, and MCFC3 Bcl-xL GFP-overexpressing cells after treatment with the same drug are also shown. The percentage of cyt. $c$ releasing cells observed in each group were counted from above experiments and shown as graph $(n=3$, mean \pm S.D.). MCFC3 versus MCFC3Bcl-2-GFP cells and MCFC3 versus MCFC3Bcl-xL-GFP cells $(P<0.001)$ for $12 \mathrm{~h}$ and $(P<0.005)$ for $24 \mathrm{~h}$ treatment. Cyt. $c$ release was checked by western blot in cytosolic fraction of MCFC3 vector, MCFC3 Bcl-2 GFP and MCFC3 Bcl-xL GFP-overexpressing cells after treatment with PAC-1 with different time points 
Furthermore, Bcl-2 and $\mathrm{Bcl}-\mathrm{xL}$ overexpression could not prevent caspase-3, 7, 2 and 8 activation, although it was delayed (Figure $5 d$ ). Also, there was only slight reduction and delay in cyt. $c$ release in $\mathrm{Bcl}-\mathrm{xL}$ and $\mathrm{Bcl}-2$-overexpressing cells as shown by immunoblot and immunofluoroscence (Figure 5e). These results clearly indicated that PAC-1 can induce cyt. $c$ release, subsequent caspase activation and thereby cell death by bypassing $\mathrm{Bcl}-2$ and $\mathrm{Bcl}-\mathrm{xL}$ inhibitory function.

\section{Effective cell death in Bak and Bax-deficient mouse} embryonic fibroblasts. Theoretically, if direct caspase activation in cancer cells is possible by small molecules; they are likely to generate active caspases in the cells downstream of Bax/Bak dependent cyt. $c$ release. A recently reported direct caspase activator 1541 has been shown to induce cell death in multidrug-resistant mouse embryonic fibroblasts (MEFs) deficient for both Bax and Bak. ${ }^{6}$ However, previously several classes of compounds have also been reported to induce cell death in Bax and Bak-deficient cells by a mitochondria-dependent or -independent manner. ${ }^{23,24}$ This necessitates precise definition of apoptosis signaling in this model system to ascertain mitochondria-dependent or independent cell death induction by such compounds. As PAC-1 was able to bypass Bcl-2- and Bcl-xL-mediated mitochondrial protection, we were interested to know if it can induce death in Bax/Bak double-knockout (DKO) cells (Figure 6a) with the same efficacy as its wild-type counterpart. Nuclear condensation, annexin staining and clonogenicity assay indicated clearly that PAC-1 induces significant cell death in DKO cells but in a delayed manner than WT cells (Figures $6 b-d)$. Furthermore, analysis of caspase activation (Figure 6f) and DEVD cleavage (Figure 6e) by immunoblot and flow cytometry using intracellular caspase substrate (Supplementary Figure S6c) suggested that PAC-1 induces caspase-3, 7, 9 and 2 activation in DKO cells, although in a delayed manner than its WT counterpart.

Mostly Bax and Bak deficiency culminates in the failure of cyt. $c$ release upon apoptotic stimulus. However, there are alternative mechanisms of cyt. $c$ release independent of Bax and Bak proteins, but the molecular mechanism is still elusive. ${ }^{19}$ Therefore, we assessed cyt. $c$ release by immunoblotting (Figure $6 \mathrm{~g}$ ) and immunofluorescence as well as cyt. c-EGFP-expressing DKO cells (Figure 6h and supplementary Figure S6c, bottom panel). We detected release of cyt. $c$ in DKO cells at $12 \mathrm{~h}$, which was significantly enhanced around $24 \mathrm{~h}$ after PAC-1 treatment, however, the release was early and rapid in wild-type cells. Cyt. c-EGFP release was also evident from $12 \mathrm{~h}$ onwards in DKO cells that is consistent with immunofluorescence (data not shown). These results demonstrate the ability of PAC-1 to release cyt. $c$ independent of Bax and Bak by an alternative mechanism leading to subsequent caspase-3 activation.

Essential role of Apaf-1 for caspase-3 activation. Released cyt. $c$ forms a complex with Apaf- 1 and procaspase- 9 known as apoptosome, which causes procaspase- 9 activation and subsequent caspase-3 activation. ${ }^{2}$ To confirm that cyt. $c$ release and apoptosome formation is essential for caspase activation, we employed Apaf-1 knockout MEF cells (Figure 7a) as a model system. Nuclear condensation suggested that Apaf-1 KO cells were highly resistant to PAC-1 than its WT counterpart (Figure 7b). There was no caspase- 3 activation in MEF Apaf- $1 \mathrm{KO}$ cells while significant cleavage was noticed in WT cells (Figure 7c). Interestingly, we noticed cyt. $c$ release in Apaf- $1 \mathrm{KO}$ cells without any significant nuclear condensation up to $24 \mathrm{~h}$ (Figure 7d). These results indicate that PAC-1 induces Bax/ Bak-independent cyt. $c$ release and apoptosome formation, which results into subsequent activation of caspase-3 in Apaf1 dependent manner. Overall our studies substantiate that mitochondrial cyt. $c$ is critical and essential for the caspase activation in cell system by the first direct caspase activator, identified in a cell-free system of caspase activation screen.

\section{Discussion}

Therapeutic benefit of targeting drug-resistant cancer cells by direct caspase activation can be achieved only if the compound can generate active caspases within the cell without the engagement of upstream mitochondrial events. ${ }^{18,25}$ So, compounds identified using cell-free systems of caspase activation needs to be validated for this activity using precise cellular models considering the enormous potential of similar compounds in addressing clinical drug resistance as well as in understanding the fundamentals of apoptosis signaling. Current understanding of apoptosis signaling indicates that if direct caspase activation is possible, it should generate detectable caspase activity well before the release of cyt. $c$ from mitochondria. However, it is extremely difficult to characterize this property in cellular models, primarily, because of the narrow time window between cyt. $c$ release and caspase activation, and lack of sensitive cellbased assays to identify and distinguish direct caspase

Figure 6 Induction of Bax and Bak-independent cyt. c release, caspase activation and cell death by PAC-1. (a) The expression status of Bax and Bak protein in MEF WT and DKO cells analyzed by western blot. (b) Analysis of nuclear condensation after PAC-1 $(50 \mu \mathrm{M})$ treatment in MEF WT and DKO cells by Hoechst staining. Representative images and graph are shown $(n=4$, mean \pm S.D.). MEF WT versus DKO, $12 \mathrm{~h}(P<0.0001)$ and $24 \mathrm{~h}(P<0.001)$. (c) Clonogenic survival was assessed in both cells upon PAC-1 treatment as described. Representative graph and images are shown $(n=3$, mean \pm S.D.). MEF WT versus DKO $(P<0.001)$. (d) Analysis of annexin $V-P E$ staining in MEF WT and DKO cells by flow cytometry after treatment with PAC-1. Shifting of population towards right suggests the annexin exposure to cell surface. (e) MEF WT and DKO cells are transiently transfected with CFP-DEVD-YFP FRET probe and treated with PAC-1 for indicated time points. DEVD cleavage was detected by western blot after PAC-1 treatment by probing with GFP antibody. (f) Caspase activation was analyzed in MEFs cell by western blot upon PAC-1 treatment for different time points. Caspase-3, $-7,-9,-2,-8$ and Bid-specific antibodies were used. HSC-70 or $\beta$ - actin served as loading control. (g) Cyt. c release was analyzed in cytosolic fraction of digitonin permeabilized MEFs cells by western blot after PAC-1 $(50 \mu \mathrm{M})$ treatment in time-dependent manner. (h) MEF DKO cells were transiently transfected with cyt. $c$-EGFP plasmid and imaged under fluorescent microscope after PAC-1 treatment for $24 \mathrm{~h}$ (scale bar: $20 \mu \mathrm{m}$ ). The diffuse pattern of cyt. $c$-EGFP in treated cells indicates its release from mitochondria to cytosol while granular pattern in untreated cells indicates its mitochondrial location 
activation from indirect. ${ }^{10,26,27}$ We have generated certain cell-based tools using caspase-specific FRET probe and EGFP-fused cyt. $c$, to identify compounds that can induce caspase activation well before cyt. $c$ release. Closer analysis of the results of cyt. $c$ release and caspase activation in real time by employing these cell-based tools indicate that cyt. $c$ release preceded caspase activation upon small molecule PAC-1 treatment similar to other drugs. Quite interestingly, PAC-1 initiated cyt. $c$ release at the same time point in both caspase-3-expressing and -deficient MCF7 cells. Intracellular caspase-3, 7 substrate and cell-death analysis again clarified that caspase activation is a later event when a

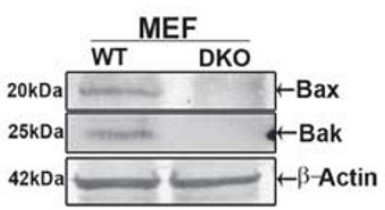

b

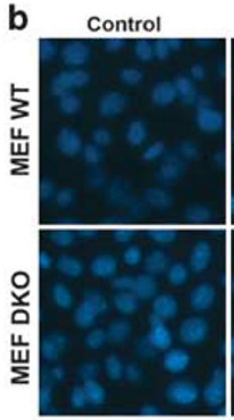

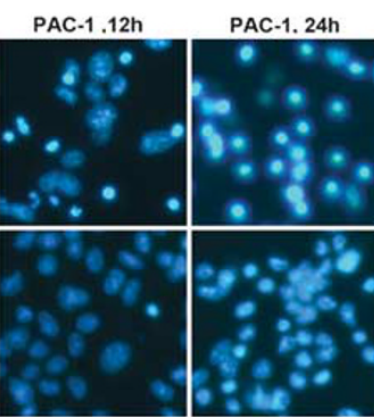
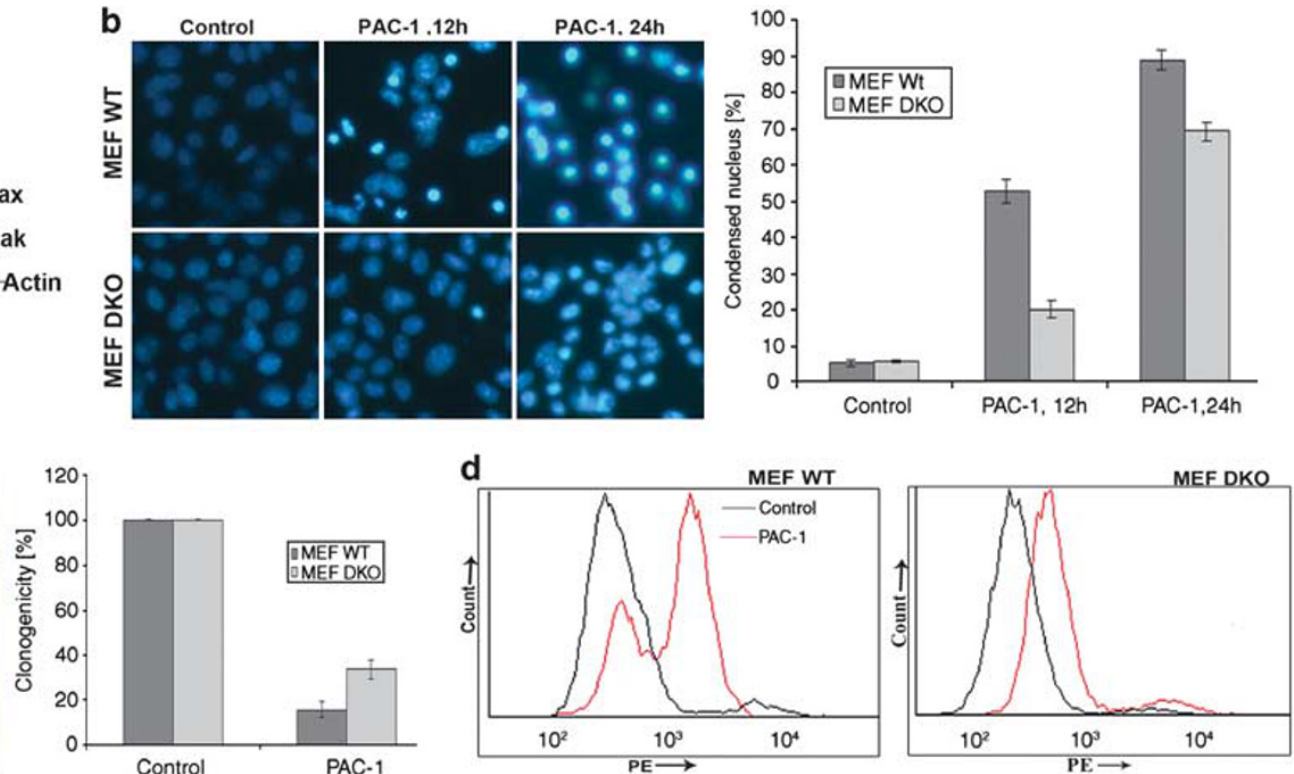

g
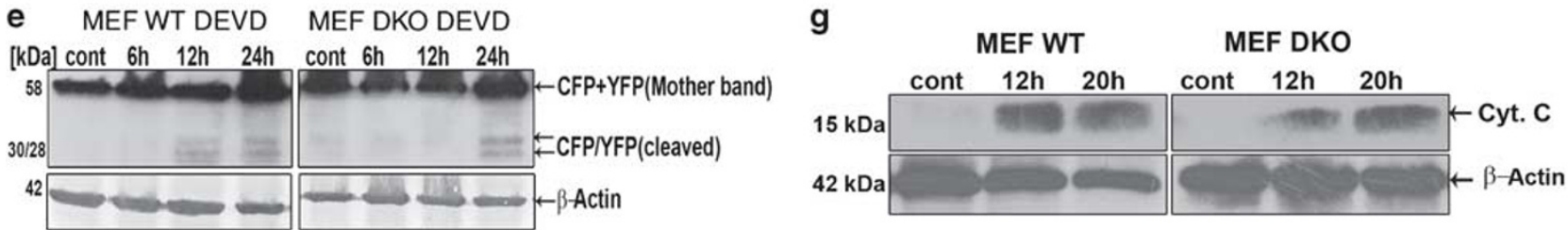

f
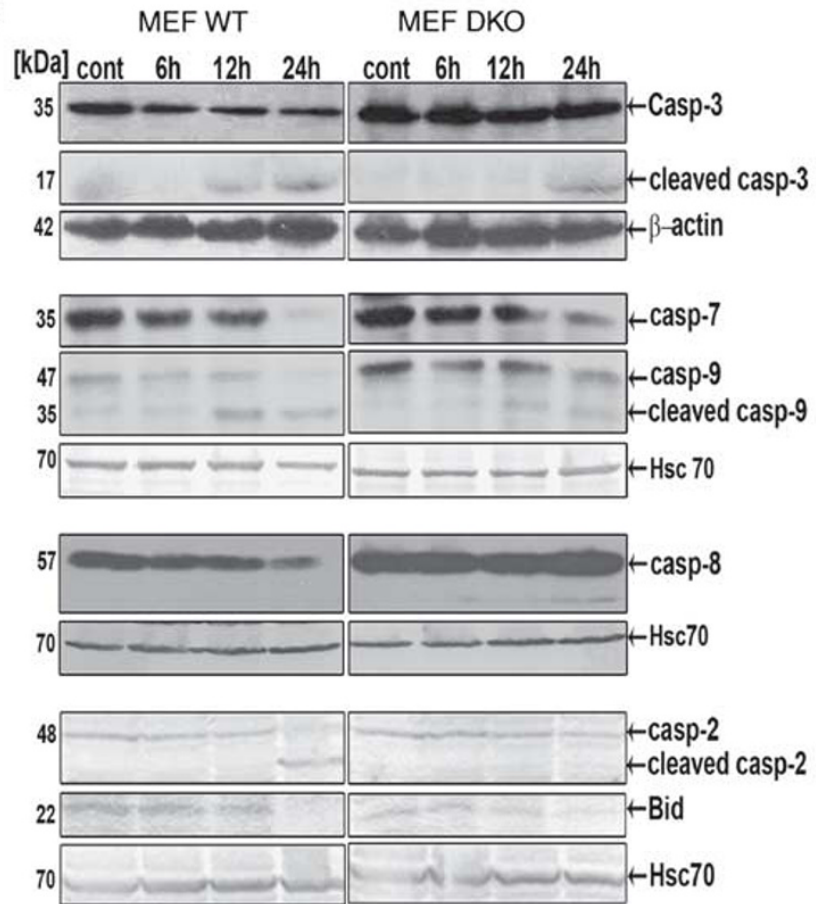

h
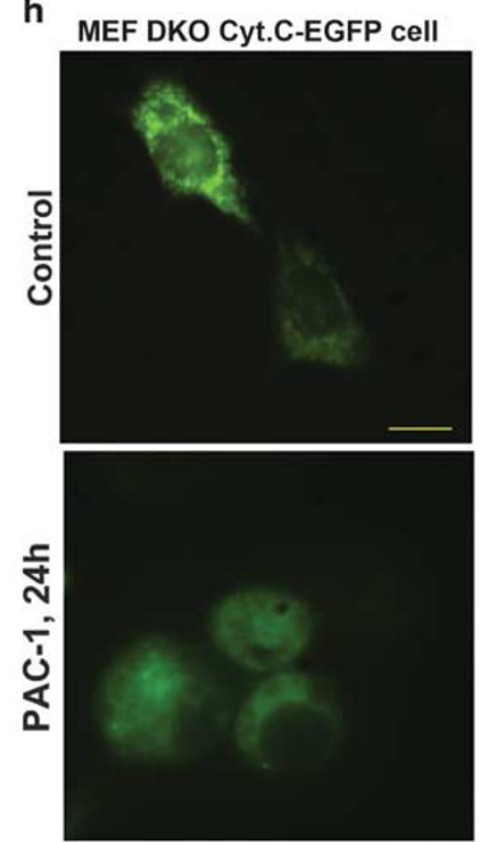
a

b
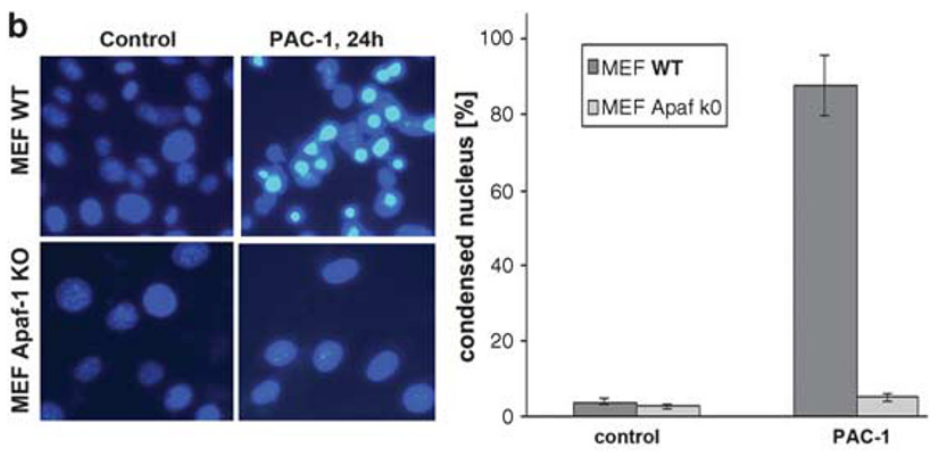

C

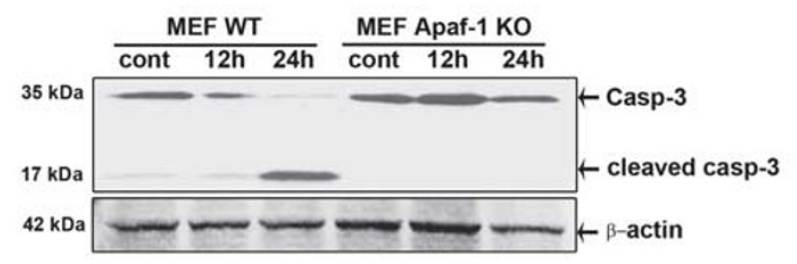

d
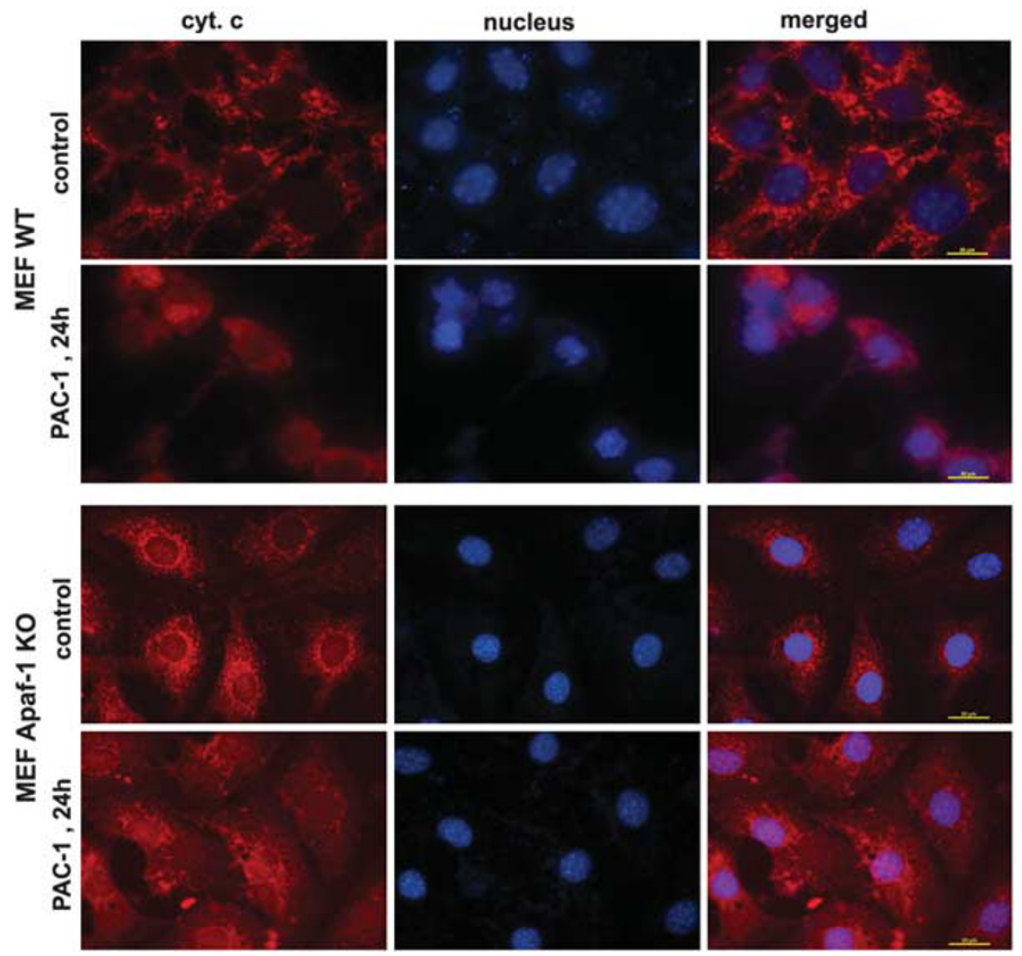

Figure 7 Absence of Apaf-1 prevented cell death and caspase-3 activation. (a) Confirmation of Apaf-1 knock-out cell and its wild-type counterpart by analyzing expression status of Apaf-1 by western blot. Apaf-1 protein was absent in knockout cells as shown in blot. (b) The cell death was assessed by nuclear condensation using Hoechst staining in MEF WT and MEF Apaf-1KO cells after PAC-1 $(50 \mu \mathrm{M})$ treatment. The condensed nuclei were counted and percentage has been plotted graphically relative to its control. Representative images and graph are shown. There was no sign of cell death in MEF Apaf-1KO cells while MEF WT cells were completely dead $(n=4$, mean \pm S.D.; $P<0.0001$ ). (c) Caspase-3 cleavage was checked in both the cells after PAC-1 treatment by western blot. Caspase-3 cleavage was absent in Apaf- $1 \mathrm{KO}$ cell while wild-type cells showed the $17 \mathrm{kDa}$ band of cleaved caspase- 3 clearly. (d) The cyt. $c$ release was checked by immunofluorescence in MEF WT and Apaf- 1 KO cells. Cyt. $c$ release and nuclear condensation were massive in WT cells, but in Apaf-1 KO cells nuclear condensation was absent even though cyt. $c$ released was noticed slightly after treatment for $24 \mathrm{~h}$ (scale bar: $20 \mu \mathrm{m}$ )

compared with cyt. $c$ release and as reported previously; PAC-1 can induce apoptosis even in caspase-3-deficient MCF7 cell although it was delayed than caspase-3-expressing MCF7 cell. ${ }^{28}$ It is well known that MCF7 cell is relatively insensitive to many cancer chemotherapy drugs and reconstitution of caspase- 3 sensitizes MCF7 cells to druginduced apoptosis. ${ }^{29}$
The time between cyt. $c$ release and caspase activation varies significantly between cells in response to multiple drugs, including first procaspase-3 activating compound 1 and 2 . SW480 cells presented with a wider time gap suggesting possible post cyt. $c$ negative regulators of caspase- 3 in this cell. Similarly, caspase-3-deficient breast cancer cell MCF7 also showed marked time delay between cyt. $c$ release and 
caspase activation marking these two systems as easy models to characterize cyt. $c$-independent caspase activation with the image-based platforms.

Previously evidence of late $\Delta \psi_{\mathrm{m}}$ loss after caspase activation carried out by independent cell population-based experiments was used for indirect measure of direct caspase activation. ${ }^{7}$ In contrast, our time-lapse imaging, flow cytometric analysis and high-throughput imaging data indicate that PAC-1 induces $\Delta \psi_{\mathrm{m}}$ loss before cyt. $c$ release, Bax translocation and caspase activation. Interestingly, PAC-1 could not induce cell death and caspase- 3 activation in the absence of Apaf-1, suggesting that apoptosome formation is essential for caspase-3 activation by PAC-1-mediated cell death. This observation and failure to reduce cyt. $c$ release in caspase inhibitor-treated cells, rules out the role of any undetectable residual caspase activity on cyt. $c$ release by feedback. Even though PAC-1 did not activate caspase-3 directly, our results reveal that $\mathrm{Bcl}-2$ and $\mathrm{Bcl}-\mathrm{xL}$-overexpressing cells were also killed by PAC-1 through cyt. $c$ release and caspase activation. Moreover, PAC-1 can also induce Bax and Bak-independent cyt. $c$ release and caspase activation although currently the mechanism behind this, is not clear. The probable role of other initiator caspases like caspase- 8 is indirectly ruled out by utilizing Apaf- $1 \mathrm{KO}$ cells in which we failed to find caspase-3 activation and cell death. We also failed to observe any Bid translocation by live-cell imaging of MCF7 Bid-DsRed-expressing cells, which again ruled out the role of caspase-8.

We define for the first time, cell-based tools to identify nonclassical apoptosis inducers with direct caspase-activating potential without any ambiguity. The results also indicate that the most important key molecular events expected from such compounds like detection of activated caspases earlier to cyt. $c$ release and apoptosome formation should be thoroughly established in kinetic mode in validating direct caspase activators. Given the clinical potential of direct caspase activators, it is essential to screen large compound libraries for identifying positive hits using such defined cellular models. As the model systems described here are adaptable for high-throughput screening, it is expected to accelerate the discovery of novel direct caspase activators in cellular systems to address clinical drug resistance.

\section{Materials and Methods}

Cell culture maintenance and treatment. Breast cancer cell line MCF7 $(\mathrm{NCl}$, Bethesda, MD, USA), colon cancer cell line SW480 and cervical cancer cell line SiHa (ATCC, Manassas, VA, USA) were maintained in Dulbecco's Modified Eagle's medium containing $10 \% \mathrm{FBS}$ in a humidified $\mathrm{CO}_{2}$ incubator at $37^{\circ} \mathrm{C}$. Immortalized murine MEF wild type and respective Bax/Bak knockout (MEF DKO) were provided by Stanely J. Korsemeyer (Harvard Medical School, Boston, MA, USA) and MEF Apaf-1 KO cells were provided by Dr Tak W Mak, Ontario Cancer Institute (Canada). MEFs cells were maintained in DMEM supplemented with $10 \%$ FBS and antibiotics.

PAC-1 (Calbiochem, San Diego, CA, USA) was used in the concentration range of 50-100 $\mu \mathrm{M}$ according to the cell line. Other drugs like staurosporine $(1 \mu \mathrm{M})$, etoposide $(50 \mu \mathrm{M})$, trichostatin $\mathrm{A}(4 \mu \mathrm{M})$, cis-platin $(50 \mu \mathrm{g} / \mathrm{ml})$, camptothecin $(5 \mu \mathrm{M})$, colchicine $(5 \mu \mathrm{g} / \mathrm{ml})$, actinomycin D $(10 \mu \mathrm{M})$ and MG132 $(10 \mu \mathrm{M})$ were purchased from Sigma (St. Louis, MO, USA). Caspase inhibitor VI $(10 \mu \mathrm{M})$ was purchased from Calbiochem.

Plasmids and generation of stable cell lines. Full-length mouse cyt. $c$ cloned in pEGFP-N1 vector was kindly provided by Dr Douglas Green (St. Jude Children's Research Hospital, Memphis, TN, USA). SW480, SiHa, MCF7 and MCF C3 were transfected with this plasmid using lipofectamine 2000 plus (Invitrogen,
Carlsbad, CA, USA) as per the manufacture's instruction, and selected in $800 \mu \mathrm{g} / \mathrm{ml}$ of G418-containing medium for 1 month. Only the clone that expressed cyt. $c$-EGFP with the correct mitochondrial targeting were further expanded and used for the study. The correct mitochondrial localization was verified by staining the cells with Mitotracker deep Red (Invitrogen) or reexpressing with MitoDsRed (Clontech, Mountain View, CA, USA).

Caspase-3 specific FRET probe pcDNA 3 DEVD (ECFP-DEVD-EYFP) plasmid was kindly provided by $\mathrm{Dr}$ Gavin Welsh (University of Bristol, UK). Cells were transfected with Lipofectamine using a standard protocol. After sorting by FACS, cells were maintained in G418-containing medium. Many clones were selected, expanded and studied for functional competence by FRET imaging after treating with standard anticancer drugs. The best clone with optimum FRET value for imaging was selected for the study.

The expression vectors pCDNA3 Bcl2- EGFP, Bcl-xL-EGFP and Bax EGFP, provided by $\mathrm{Dr}$ Clark Distelhorst were transfected in MCFC3 cells using lipofectamine and maintained in G418 selection medium. Bid DsRed (Clontech) was transfected in MCF7 cells to generate stable clones as described above. The plasmid pCDNA3 caspase-3 was provided by Dr VM Dixit (Genentech, USA) and transfected in MCF7 cells as described, and positive clones were selected by maintaining in G418.

Live-cell imaging. Cells were grown on chambered cover glass (Lab-Tek, Nunc, Rochester, NY, USA), to which the indicated drugs reconstituted in DMEM containing $5 \% \mathrm{FBS}$ was added. For imaging, cells were stained as described and imaged in a live-cell incubation chamber (Tokai Hit, Shizuoka-ken, Japan) that maintains optimum $\mathrm{CO}_{2}$, temperature and humidity. Imaging was carried out using a $\times 20$ Plan Apo $1 \mathrm{NA}$ objective under an inverted fluorescence microscope (Nikon Eclipse, TE2000-E, Tokyo, Japan) equipped with a CARV II confocal imager (Becton Dickinson (BD) Mount View, CA, USA) and an automated excitation and emission filter wheel. The images were captured using EMCCD camera Andor iXON 885 using IPLab software (BD) at regular intervals for the indicated time periods. To minimize photobleaching, the intensity of the light was reduced to $1 \%$ by intensity iris control.

For live-cell imaging of cyt. $c$, the cells were grown on chambered cover glass as described earlier and treated with drugs. After drug treatment, the cells were imaged using TE2000 E fluorescent microscope using Retiga Exi (Q. Imaging, Surrey, BC, Canada) camera at regular intervals using NIS Element software. For live-cell imaging of TMRM and cyt. $c$-EGFP or Bax, the respective cells were stained with $100 \mathrm{nM}$ of TMRM (Molecular Probes, \#T-668, Eugene, OR, USA) followed by imaging in drug and $20 \mathrm{nM}$ of TMRM containing medium. For ratio imaging of CFPYFP FRET, CFP was excited with $438 \pm 12 \mathrm{~nm}$ band pass filter, and dual emission was collected at $480 \pm 15 \mathrm{~nm}$ band pass filter for CFP channel and EYFP-FRET channel with $542 \pm 27 \mathrm{~nm}$ band pass filter.

Immunoblotting. After treatment with drugs, cells were lysed in lysis buffer containing $1 \%$ NP-40 and protease inhibitor cocktail by incubating in ice for $30 \mathrm{~min}$. Proteins were estimated by using Bradford reagent and $40 \mu \mathrm{g}$ of proteins were resolved electrophoretically on $8-15 \%$ SDS polyacrylamide gels, transferred to nitrocellulose membranes and detected by chemiluminescence (Amersham, Buckinghamshire, UK) or by Diamino benzedine (Sigma).

For analyzing cyt. $c$ release from mitochondria, cells were permeabilized with digitonin containing cytosolic extraction buffer with different concentration $(40-150 \mu \mathrm{g} / \mathrm{ml})$ depending on the cell, and supernatant(free of mitochondria) was obtained by centrifugation at 15000 r.p.m. for $30 \mathrm{~min}$ and then again 15000 r.p.m. for $5 \mathrm{~min}$. Cytosolic fraction (supernatant) was resolved on 15\% SDS-PAGE gel.

The following primary antibodies were used for immunoblotting and immunofluorescence: Caspase 3 (9662), cleaved caspase 3 (9661), caspase 9 (9502), cleaved caspase 9 (9505), mouse-specific caspase 9 (9504), mousespecific cleaved caspase 9 (9509), caspase 8 (9746), mouse-specific caspase 8 (4927), cleaved caspase 7 (9491), PARP (9542), BID (2002), caspase 2 (C2; 2224) and GFP (2555) were purchased from Cell Signaling Technology (Beverly, MA, USA). Apaf1(sc-8339), HSC70(7298), $\beta$-Actin (sc-1616), cyt. c (7H8): (sc-13560), $\operatorname{Bax}(7480), \operatorname{Bak}(832), \mathrm{Bcl}-2 \mathrm{sc}-7382$ and $\mathrm{Bcl}-\mathrm{XL}(\mathrm{sc}-7195)$ were purchased from Santa Cruz Biotechnology (Santa Cruz, CA, USA). Caspase 2 (clone 10C6) from Chemicon (Temecula, CA, USA). Cyt. c (6H2.B4) from BD Bioscience (San Diego, CA, USA) was used for the study.

Immunofluorescence. Cells were seeded in 96-well glass-bottom plates (Whatman, Clifton, NJ, USA) and fixed with ice-cold acetone:methanol (1:1) for $10 \mathrm{~min}$. After blocking with $3 \% \mathrm{BSA}$, cells were incubated with anti-cyt. c (6H2.B4) at 
$37^{\circ} \mathrm{C}$ for $3 \mathrm{~h}$ followed by secondary antibody conjugated with alexa fluor 594 (Molecular Probes). After $1 \mathrm{~h}$ incubation, cells were washed with PBS and imaged using fluorescent microscope TE 2000E using specific filter combinations.

High-throughput Imaging. Cells were seeded in a 96-well glass-bottom plate $(\mathrm{BD})$ and after $48 \mathrm{~h}$, stained with TMRM $(50 \mathrm{nM})$ and then treated with different drugs along with low concentration of TMRM $(20 \mathrm{nM})$. Images were captured using BD Pathway Bioimager 435 with different time points by setting $3 \times 3$ montage and specific Macro using AttoVision software. Both TMRM intensity and FRET ratio intensity for caspase-3, 7 specific FRET probe were analyzed after proper segmentation from scatter plot. For imaging of CFP-DEVD-YFP, the Pathway Bioimager was configured with ECFP Ex: $438 \pm 12 \mathrm{~nm}$ band pass filter Dichroic: 458 LP and dual emission at $483+15 \mathrm{~nm}$ for CFP, $542 \pm 27 \mathrm{~nm}$ for EYFP FRET was collected by automated filter wheel combinations in ratio mode acquisition.

Analysis of chromatin condensation. After treatment with drugs, the cells were stained with Hoechst 33342 stain $(1 \mu \mathrm{g} / \mathrm{ml})$ and incubated for $10 \mathrm{~min}$ at $37^{\circ} \mathrm{C}$ and images were taken under UV filter using Epi-fluorescent Microscope (Nikon TE 2000E). Condensed nucleus was counted against total number of nucleus in the field, and the percentage of apoptotic nuclei were calculated and plotted graphically.

Flow cytometry analyses. Loss of $\Delta \psi_{\mathrm{m}}$ was measured by using the fluorescent dye TMRM. After treatment with drugs, cells were trypsinized and centrifuged at 3000 r.p.m. for 5 min and once again washed with OPTIMEM medium. Cells were then incubated for $10 \mathrm{~min}$ at $37^{\circ} \mathrm{C}$ after adding OPTIMEM medium containing TMRM dye (molecular probes) with $50 \mathrm{nM}$ and analyzed by FACS Aria1 (Becton Dickinson).

Apoptotic cells were quantified on a single cell basis by FACS using PE conjugated Annexin V (BD PharMingen, San Diego, CA, USA). After treatment, cells were harvested by trypsinization and washed with $1 \times$ annexin binding buffer and then stained with PE conjugated annexin V (red fluorescence) and incubated for 30 min at $37^{\circ} \mathrm{C}$. Total 20000 cells were evaluated for annexin binding by FACS Aria.

Intracellular caspases activity was detected by using caspases detection kit from Calbiochem and Chemicon International. Red-LEHD-FMK (caspase 9), Red-IETDFMK(caspase 8), caspase 2 fluorescein and CaspaTag sulforhodamine (caspase 3,7) substrates were used as per the kit protocol for staining the cells and analyzing by FACS.

Clonogenicity assays. The colony-forming potential of adherent cells was measured as described previously (Janssen et al., 2007). Briefly, cells were seeded in six-well plates with $50 \%$ confluency and treated with PAC1 on the following day. After 24 or $48 \mathrm{~h}$, cells were washed and maintained in normal medium for another $24 \mathrm{~h}$ until the untreated controls reached more than $90 \%$ confluency. Cells were split and reseeded with $1: 100$ dilution in new plates. After 5 or 7 days, viable cells were stained with $0.5 \%$ Crystal Violet and solubilized in $33 \%$ acetic acid. Absorbance was measured at $590 \mathrm{~nm}$ (A590). Relative proliferation was defined as A590 of test well $\times 100$ divided by the $A 590$ of untreated well.

\section{Conflict of Interest}

The authors declare no conflict of interest.

Acknowledgements. This study was supported by grants from the Innovative Young Biotechnologist Award, Deptartment of Biotechnology, Government of India, Research Fellowship from UGC and CSIR, Government of India. We thank Professor M Radhakrishna Pillai and the lab members for helping throughout, Mrs Indu and Mr Saravanan for FACS analysis, Jissa VT for statistical analysis, Dr Paresh Jain, BD India for his support in pathway imaging. We thank Dr Douglas Green, Dr Clark Distelhorst, Dr VM Dixit and Dr Gevin Welsh for the plasmids. We also thank Dr Stanley Korsemeyer and Dr Tak W Mak for the cell lines used in the study.

1. Ow YP, Green DR, Hao Z, Mak TW. Cytochrome c: functions beyond respiration. Nat Rev Mol Cell Biol 2008; 9: 532-542.

2. Riedl SJ, Salvesen GS. The apoptosome: signalling platform of cell death. $\mathrm{Nat}$ Rev $\mathrm{Mol}$ Cell Biol 2007; 8: 405-413.

3. Wei MC, Zong WX, Cheng EH, Lindsten T, Panoutsakopoulou V, Ross AJ et al. Proapoptotic BAX and BAK: a requisite gateway to mitochondrial dysfunction and death. Science 2001; 292: 727-730.

4. Yip KW, Reed JC. Bcl-2 family proteins and cancer. Oncogene 2008; 27: 6398-6406.

5. Zorn JA, Wells JA. Turning enzymes ON with small molecules. Nat Chem Biol 2010; 6 : 179-188.

6. Wolan DW, Zorn JA, Gray DC, Wells JA. Small-molecule activators of a proenzyme. Science 2009; 326: 853-858.

7. Putt KS, Chen GW, Pearson JM, Sandhorst JS, Hoagland MS, Kwon JT et al. Smallmolecule activation of procaspase- 3 to caspase-3 as a personalized anticancer strategy. Nat Chem Biol 2006; 2: 543-550.

8. Peterson QP, Goode DR, West DC, Ramsey KN, Lee JJ, Hergenrother PJ. PAC-1 activates procaspase-3 in vitro through relief of zinc-mediated inhibition. $\mathrm{J} \mathrm{Mol} \mathrm{Biol} \mathrm{2009;}$ 388: $144-158$.

9. Peterson QP, Hsu DC, Goode DR, Novotny CJ, Totten RK, Hergenrother PJ. Procaspase3 activation as an anti-cancer strategy: structure-activity relationship of procaspaseactivating compound 1 (PAC-1) and its cellular co-localization with caspase-3. J Med Chem 2009; 52: 5721-5731.

10. Kawai $\mathrm{H}$, Suzuki $\mathrm{T}$, Kobayashi $\mathrm{T}$, Ishii-Watabe $\mathrm{A}$, Sakurai $\mathrm{H}$, Ohata $\mathrm{H}$ et al. Caspase cascade proceeds rapidly after cytochrome $\mathrm{c}$ release from mitochondria in tumor necrosis factor-alpha-induced cell death. J Pharmacol Sci 2007; 103: 159-167.

11. Lakhani SA, Masud A, Kuida K, Porter Jr GA, Booth CJ, Mehal WZ et al. Caspases 3 and 7 : key mediators of mitochondrial events of apoptosis. Science 2006; 311: 847-851.

12. Bossy-Wetzel E, Newmeyer DD, Green DR. Mitochondrial cytochrome c release in apoptosis occurs upstream of DEVD-specific caspase activation and independently of mitochondrial transmembrane depolarization. EMBO J 1998; 17: 37-49.

13. Tait SW, Bouchier-Hayes L, Oberst A, Connell S, Green DR. Live to dead cell imaging Methods Mol Biol 2009; 559: 33-48.

14. Tian $H$, Ip L, Luo $H$, Chang DC, Luo KQ. A high throughput drug screen based on fluorescence resonance energy transfer (FRET) for anticancer activity of compounds from herbal medicine. Br J Pharmacol 2007; 150: 321-334.

15. Lin J, Zhang Z, Yang J, Zeng S, Liu BF, Luo Q. Real-time detection of caspase-2 activation in a single living HeLa cell during cisplatin-induced apoptosis. J Biomed Opt 2006; 11: 024011.

16. Kawai H, Suzuki T, Kobayashi T, Sakurai H, Ohata H, Honda K et al. Simultaneous realtime detection of initiator- and effector-caspase activation by double fluorescence resonance energy transfer analysis. J Pharmacol Sci 2005; 97: 361-368.

17. McStay GP, Salvesen GS, Green DR. Overlapping cleavage motif selectivity of caspases: implications for analysis of apoptotic pathways. Cell Death Differ 2008; 15: 322-331.

18. Tait SW, Green DR. Mitochondria and cell death: outer membrane permeabilization and beyond. Nat Rev Mol Cell Biol 2010; 11: 621-632.

19. Garrido C, Galluzzi L, Brunet M, Puig PE, Didelot C, Kroemer G. Mechanisms of cytochrome c release from mitochondria. Cell Death Differ 2006; 13: 1423-1433.

20. Chelur DS, Chalfie M. Targeted cell killing by reconstituted caspases. Proc Natl Acad Sci USA 2007; 104: 2283-2288.

21. Nguyen JT, Wells JA. Direct activation of the apoptosis machinery as a mechanism to target cancer cells. Proc Natl Acad Sci USA 2003; 100: 7533-7538.

22. Cartron PF, Juin $P$, Oliver L, Meflah K, Vallette FM. Impact of proapoptotic proteins Bax and Bak in tumor progression and response to treatment. Expert Rev Anticancer Ther 2003; 3: 563-570.

23. Lomonosova E, Ryerse J, Chinnadurai G. BAX/BAK-independent mitoptosis during cell death induced by proteasome inhibition? Mol Cancer Res 2009; 7: 1268-1284.

24. Lei X, Chen Y, Du G, Yu W, Wang X, Qu H et al. Gossypol induces Bax/Bak-independent activation of apoptosis and cytochrome $\mathrm{c}$ release via a conformational change in $\mathrm{Bcl}-2$. FASEB J 2006; 20: 2147-2149.

25. Desagher S, Martinou JC. Mitochondria as the central control point of apoptosis. Trends Cell Biol 2000; 10: 369-377.

26. Taylor RC, Cullen SP, Martin SJ. Apoptosis: controlled demolition at the cellular level. Nat Rev Mol Cell Biol 2008; 9: 231-241.

27. Green $D$, Kroemer $G$. The central executioners of apoptosis: caspases or mitochondria? Trends Cell Biol 1998; 8: 267-271.

28. Denault JB, Drag M, Salvesen GS, Alves J, Heidt AB, Deveraux $Q$ et al. Small molecules not direct activators of caspases. Nat Chem Biol 2007; 3: 519; author reply 520.

29. Yang XH, Edgerton S, Thor AD. Reconstitution of caspase-3 sensitizes MCF-7 breast cancer cells to radiation therapy. Int J Oncol 2005; 26: 1675-1680.

(c)

SOMERIEHTS RESERVED licensed under the Creative Commons Attribution-Noncommercial-No Derivative Works 3.0 Unported License. To view a copy of this license, visit http://creativecommons.org/licenses/by-nc-nd/3.0/ 